\title{
Toll like receptors TLR1/2, TLR6 and MUC5B as binding interaction partners with cytostatic proline rich polypeptide 1 in human chondrosarcoma
}

\author{
KARINA GALOIAN $^{1}$, SILVA ABRAHAMYAN ${ }^{2}$, GOR CHAILYAN $^{2}$, AMIR QURESHI $^{1}$, PARTHIK PATEL ${ }^{1}$, \\ GIL METSER $^{1}$, ALEXANDRA MORAN ${ }^{1}$, INESA SAHAKYAN ${ }^{2}$, NARINE TUMASYAN ${ }^{2}$, ALBERT LEE $^{2}$, \\ TIGRAN DAVTYAN ${ }^{3}$, SAMVEL CHAILYAN ${ }^{2}$ and ARMEN GALOYAN ${ }^{2 *}$
}

\author{
${ }^{1}$ Department of Orthopedic Surgery, University of Miami Miller School of Medicine, Miami, FL, USA; ${ }^{2}$ Buniatian Institute \\ of Biochemistry Academy of Sciences of Armenia, Yerevan 0014; ${ }^{3}$ Analytical Laboratory Branch of E. Gabriyelian \\ Scientific Center of Drug and Medical Technology Expertise of Ministry Health of Armenia, Yerevan 0002, Armenia
}

Received September 13, 2017; Accepted October 27, 2017

DOI: 10.3892/ijo.2017.4199

\begin{abstract}
Metastatic chondrosarcoma is a bone malignancy not responsive to conventional therapies; new approaches and therapies are urgently needed. We have previously reported that mTORC1 inhibitor, antitumorigenic cytostatic proline rich polypeptide 1 (PRP-1), galarmin caused a significant upregulation of tumor suppressors including TET1/2 and SOCS3 (known to be involved in inflammatory processes), downregulation of oncoproteins and embryonic stem cell marker miR-302C and its targets Nanog, c-Myc and Bmi-1 in human chondrosarcoma. To understand better the mechanism of PRP-1 action it was very important to identify the receptor it binds to. Nuclear pathway receptor and GPCR assays indicated that PRP-1 receptors are not G protein coupled, neither do they belong to family of nuclear or orphan receptors. In the present study, we have demonstrated that PRP-1 binding interacting partners belong to innate immunity pattern recognition toll like receptors TLR1/2 and TLR6 and gel forming secreted mucin MUC5B. MUC5B was identified as PRP-1 receptor in human chondrosarcoma JJ012 cell line using Ligand-receptor capture technology. Toll like receptors TLR1/2 and TLR6 were identified as binding interaction partners with PRP-1 by western blot analysis in human chondrosarcoma JJ012 cell line lysates. Immunocytochemistry experiments confirmed the finding and indicated the localization of PRP-1 receptors in the tumor nucleus predominantly. TLR1/2, TLR6 and
\end{abstract}

Correspondence to: Professor Karina Galoian, Department of Orthopedic Surgery, University of Miami Miller School of Medicine, 1600 NW 10th Avenue 1140, Miami, FL 33136, USA

E-mail:kgaloian@med.miami.edu

\section{"Deceased}

Key words: PRP-1, galarmin, receptors, innate immunity, chondrosarcoma, TLR1/2, TLR6, MUC5B
MUC5B were downregulated in human chondrosarcoma and upregulated in dose-response manner upon PRP-1 treatment. Experimental data indicated that in this cellular context the mentioned receptors had tumor suppressive function.

\section{Introduction}

Chondrosarcoma is cancer of the cartilage that eventually metastasize. The disease can affect multiple organs, such as long bones, spine, pelvis, larynx and head. Conventional therapies are not effective in this disease treatment and there is urgency in seeking new approaches $(1,2)$. The signaling events resulting in mesenchymal cell transformation to sarcoma have yet to be fully elucidated. Proline rich polypeptide 1, (PRP-1), also known as (galarmin) is produced by the brain neurosecretory cells and comprised of 15 amino acids (3), and is a mTOR kinase (mTORC1) inhibitor in chondrosarcoma, which causes $80-90 \%$ inhibition of chondrosarcoma cell growth, halting G1/S phase cell cycle progression in chondrosarcoma $(4,5)$ and other mesenchymal tumors (6). The ability of PRP-1 to upregulate tumor suppressor miRNAs and downregulate onco-miRNAs in human chondrosarcoma JJ012 cell line was demonstrated (7). The upregulation of most tumor suppressors in chondrosarcoma (8) including inflammation related TET1/2 and SOCS3 is one of the unique PRP-1 properties, however, it depends on which molecular pathway these tumor suppressors are part of (9). PRP-1 epigenetically downregulates embryonic stem cell marker miR-302c in human chondrosarcoma and its targets Nanog, c-Myc and Bmil (10). To understand better the mechanism of PRP-1 action and its potential as therapeutic agent in the future, it is very important to identify the receptor it binds to. In the present study, we present evidence that PRP-1 exerts its effect via interacting with toll like receptor family TLR1/2, TLR6 and mucin MUC5B. Innate immunity toll-like receptors (TLRs), or pattern recognition receptors are sensitive both to endogenous and exogenous ligands $(11,12)$ and can be found both inside the cells and at the cell surface. Intracellular TLRs start their journey from the endoplasmic reticulum (ER) through the Golgi and eventually to endolysosomes (13). TLRs 
play active roles in carcinogenesis and tumor progression or its inhibition $(14,15)$ where the activation of TLR signalling could regulate antitumor immunity of the host (16). The term alarmins is often used when referring to endogenous TLR ligands. The innate immune system can be activated by recognizing pathogen associated molecular patterns (PAMPs). The injured cells in their turn have ability to release dangerassociated molecular patterns (DAMPs) and contribute to the activation of innate immune system. Thus, immune system is involved not only in fighting the infection by mobilizing the immunologic arsenal, but also in the process of tissue repair. Hence, the term non-infectious inflammation response, whenever TLR signaling is mediated by endogenous ligands, which secure autoimmune disease and tumorigenesis in addition to tissue repair and injury $(17,18)$. TLRs1 (cluster of differentiation 281), 2, 4, 5 and 6 are expressed on the cell surface, whereas TLRs3, 7, 8 and 9 are intracellular nucleic acid receptors. The ligand for TLR10 remains to be found (19). The antitumorigenic role of TLR2 is recognized, its deficiency led to early intestinal tumor formation (20). Most of endogenous TLR ligands are agonists of TLR4 and TLR2 (21). There is a reported link berween TLR signaling andmucins (MUCs) leading to effective pathogen elimination (22-24). Mucins are glycosylated large extracellular proteins that are found not only in mucous cells but also in connective tissue and goblet cells. Mucin expression glycosylation alterations can lead to the development of cancer and cellular transformation (25-31). Apomucin with the attached O-linked oligosaccharides is the protein backbone for mucin. There are 'secreted (gel-forming and non-gel-forming)' and 'membrane-bound' mucins, with transmemebrane domain (32). The goblet cells from the epithelium and mucous cells from submucosal glands generate secreted mucins. Secreted mucins on the chromosome 11p15 include MUC2, MUC5AC, MUC5B, MUC6 and MUC19. Some of the mucins can manifest themselves as tumor suppressors, for example MUC4 $(33,34)$. MUC5B expression has protumorigenic $(28,35)$ or antitumorigenic consequence for the cell growth $(36,37)$ and was linked both to decreased survival or better prognosis in cancer patients correspondingly, depending on the disease and organ specificity. MUC5B was shown to have very beneficial effects in human airway defense (38). The epigenetic mechanism, hypermethylation of MUC5B promoter was attributed to the silencing of its tumor suppressor activity (39). Both overexpression and downregulation of mucins in different organs can contribute to cancer pathology and inflammation $(26,40)$.

\section{Materials and methods}

PRP-1 initial isolation and chemical synthesis. Initially, PRP-1 was isolated from the neurosecretory granules of bovine neurohypophysis by the method described $(3,41)$ followed by its chemical synthesis (42).

PRP-1 antiserum affinity chromatography purification. Antiserum for PRP1 was generated (43), then affinity chromatography purified, AminoLink Plus Immobilization kit instructions (44894; Thermo Fisher Scientific, Waltham, MA, USA) were followed for protein sample desalting with Zeba Spin columns (89891; Thermo Fisher Scientific).
Tissue culture. The human JJ012 chondrosarcoma cell line was received from Dr Joel Block's Laboratory (Rush University, Chicago IL, USA). JJ012 chondrosarcoma cells were cultured as previously described (8). The medium composition: Dulbecco's modified Eagle's medium (DMEM), supplemented with F12, 10\% fetal bovine serum (FBS), $25 \mu \mathrm{g} / \mathrm{ml}$ ascorbic acid, $100 \mathrm{ng} / \mathrm{ml}$ insulin, $100 \mathrm{nM}$ hydrocortisone and $1 \%$ penicillin/streptomycin.

Brief immunocytochemistry protocol. Adherent cells were grown directly on coverslips with $5 \times 10^{5}$ cells/coverslip in 6 -well clusters, where they were cultured overnight at $37^{\circ} \mathrm{C}$ in an incubator. Twenty-four hours later the medium was removed and samples were fixed in $1 \mathrm{ml}$ of $4 \%$ formaldehyde solution, (F8775; Sigma-Aldrich St. Louis, MO, USA) in phosphate-buffered saline (PBS), pH 7.4 1X Gibco, (10010-023) PBS for $15 \mathrm{~min}$ in the incubator. Samples were washed with PBS twice, then were permeabilized with PBS/Triton X-100 (T9284; Sigma-Aldrich), $1 \%$ for $5 \mathrm{~min}$ at room temperature. Detergent was removed and non-specific sites were blocked in PBS containing 2\% bovine serum albumin (BSA, A2153; Sigma-Aldrich) at room temperature for $30 \mathrm{~min}$. Samples were further incubated overnight in cold room along with all primary antibodies for the experiment, followed by two consecutive washes the next morning and incubation in BSA solution with secondary antibodies at room temperature for $2 \mathrm{~h}$ along with Zenon complex and two washes with PBS, for $10 \mathrm{~min}$ each. Second fixation step with formaldehyde for $15 \mathrm{~min}$ at room temperature in the dark was performed, followed by two washing steps.

Zenon complex formation. PRP-1 serum antibody and Zenon rabbit IgG, Alexa Fluor 488 (Z-25302; Molecular Probes, Eugene, OR, USA) were mixed according to the manual and the procedures. The mixture was incubated for $10 \mathrm{~min}$ at room temperature with labeling reagent $\mathrm{A}$, then another 10 min incubation with the blocking reagent $B$ and $1 \mathrm{ml}$ of the resulting mixture was applied to each well. Cells were stained with $3 \mu \mathrm{M}$ of 4',6-diamino-2-phenylindole dihydrochloride (DAPI, D1306; Thermo Fisher Scientific) for nuclear staining or $10 \mathrm{~min}$ at room temperature, the washed with PBS twice. The samples on coverslips were mounted in Antifade mounting medium, followed by microscopy. ProLong Gold Antifade reagent (P10144; Life Technologies) was applied as a liquid mountant directly to fluorescently labeled cells on microscope slides. The reagent contains chemicals to protect fluorescent dyes from fading during fluorescence microscopy.

Antibodies used for immunocytochemistry. For plasma membrane staining wheat germ agglutinin Alexa Fluor 594 conjugate was used (W11262; Thermo Fisher Scientific); TLR1 rabbit antibody (ab180798; Abcam); goat anti-rabbit H\&L (DyLight 550) (ab96884; Abcam); mouse anti-MUC5B, Abcam (ab77995); goat anti-mouse IgG secondary antibody Alexa Fluor 647 (A2124; Life Technologies).

Imaging. Image acquisition was performed by the Analytical Imaging Core Facility at DRI/SCCC, University of Miami (FL, USA). 
Zeiss 200M, ApoTome fluorescent microscope, DAPI 49, GFP 38HE, Cy3 43, Cy5 50 filter cubes, heated stage, Orca II ERG Hamamatsu b/w 14 bit camera and AxioVision acquisition software were used. The coverslips were placed in regular 35-mm Petri dishes and the cells grown on them, covered with medium. Once the cells were grown, the coverslips were taken out, the cells were fixed, stained and mounted on the glass slides. For imaging controls secondary antibodies were used without the primaries.

Human MUC5B ELISA and electrophoresis and western blotting. MUC5B protein was measured with human mucin -5 subtype (MUC5B) ELISA kit (MyBioSource, San Diego, CA, USA) (MBS 704534-48T).

The cells were trypsinized once they reached confluency and then seeded in 6-well clusters at a concentration of $1 \times 10^{6}$ cells/ml. PRP-1 was added only to the experimental samples but not to controls. The overnight incubation in $5 \% \mathrm{CO}_{2}$ incubator at $37^{\circ} \mathrm{C}$ was followed by cell wash with ice-cold PBS with added protease inhibitor. The cell lysis buffer (C2978; Sigma-Aldrich) was supplemented with the protease inhibitor in a 1:100 ratio. The cells were collected with a scraper and centrifuged at $15,000 \mathrm{xg}$ at $4^{\circ} \mathrm{C}$. The supernatant was collected and the protein concentration was measured. The pellets were frozen at $-80^{\circ} \mathrm{C}$ until loading on the gel $(20 \mu \mathrm{g} / \mathrm{lane})$. Polyacrylamide gel electrophoresis and western blotting reagents were supplied by Lonza, Inc. (Allendale, NJ, USA), and all the related procedures followed the company's protocol. The catalog numbers for the reagents and the suppliers are listed below for convenience, although they were reported in our previous communication (8). PAGEr ${ }^{\mathrm{TM}}$ Gold Precast Gels (59502; 10\% Tris-Glycine; Lonza); ECL reagent (RPN2109; GE Healthcare, Little Chalfont, UK); Western Blocker solution (W0138; Sigma-Aldrich); ProSieve QuadColor Protein marker (4.6-300 kDa, 00193837; Lonza); 20X Reducing Agent for ProSieve ProTrack Dual Color Loading buffer (00193861; Lonza); ProTrack Loading buffer (00193861; Lonza); ProSieve ProTrack Dual Color Loading buffer EX running buffer (00200307; Lonza); ProSieve EX Western Blot Transfer buffer (00200309; Lonza); Immobilon ${ }^{\circledR}$-P PVDF Membranes (P4188; Sigma-Aldrich).

Immunoblot antibodies. Rabbit polyclonal anti-TLR6 (ab37072), MW $92 \mathrm{kDa}$ (Abcam); rabbit anti-TLR1 cell (2209), MW 86 kDa (Cell Signaling Technology, Danvers, MA, USA); rabbit anti-TLR1 (ab68158), MW $90 \mathrm{kDa}$ (Abcam); mouse anti-TLR2 [TL2.1], (ab9100), MW 90 kDa (Abcam); Mouse anti-TLR3 (TLR3.7) (sc-32232), MW 104 kDa (Santa Cruz Biotechnology, Santa Cruz, CA, USA); mouse anti-TLR4 (25) (sc-293072), MW 95-120 kDa (Santa Cruz Biotechnology); mouse anti-TLR5 (19D759.2), (sc-57461), MW 110-120 kDa (Santa Cruz Biotechnology); rabbit anti-TLR7, (5632), MW 140 kDa (Cell Signaling Technology); mouse TLR 8 (9A6), (sc-135584), MW 119.8 kDa (Santa Cruz Biotechnology); rabbit anti-TLR9, (5845), MW 130 kDa (Cell Signaling Technology); mouse TLR10 (2A11), sc-293300, MW 90 kDa (Santa Cruz Biotechnology); mouse anti-tubulin, (T5168; Sigma-Aldrich); rabbit anti-TRIF/TICAM1, NBP2-31189, MW 75 kDa (Novus Biologicals, Littleton, CO, USA); mouse anti-TICAM2, MW 21 kDa (Santa Cruz Biotechnology); rabbit anti-TRAF6 (3566R-100), MW 54 kDa (BioVision, Inc., Milpitas, CA, USA); goat anti-rabbit IgG, HRP-linked (7074; Cell Signaling Technology); anti-mouse IgG, HRP-linked (7076; Cell Signaling Technology).

Lead Hunter discoveryservices (DiscoveRx). Nuclear Hormone Receptor Assays: PathHunter ${ }^{\circledR}$ NHR Protein Interaction (Pro) and Nuclear Translocation (NT) assays monitor the activation of a nuclear hormone receptor in a homogeneous, non-imaging assay format using a technology developed by DiscoveRx called enzyme fragment complementation (EFC). The company described NHR Pro assay detects of protein-protein interactions between an actvated NHR protein and a nuclear fusion protein containing steroid receptor co-activator peptide (SRCP). When bound by ligand, the NHR will migrate to the nucleus and recruit the SRCP domain, whereby complementation occurs, generating a unit of active $\beta$-galactosidase ( $\beta$-gal) and production of chemiluminescent signal.

Arrestin pathway: The PathHunter ${ }^{\circledR} \beta$-arrestin assay based on activation of a GPCR using a method developed by DiscoveRx called enzyme fragment complementation (EFC) with $\beta$-galactosidase ( $\beta$-gal) as the functional reporter (44). In brief, according to the manufacturer's protocol: the enzyme is split into two inactive complementary portions (EA for enzyme acceptor and ED for enzyme donor) expressed as fusion proteins in the cell. EA is fused to $\beta$-arrestin and ED is fused to the GPCR of interest. When the GPCR is activated and $\beta$-arrestin is recruited to the receptor, ED and EA complementation occurs, restoring $\beta$-gal activity which is measured using chemiluminescent PathHunter ${ }^{\circledR}$ detection reagents.

Data analysis. The GPCR max panel \% agonist was calculated as $100 \%$ (mean of test samples - mean of vehicle control)/mean Max control ligand - mean of vehicle control). For antagonist mode assays, percentage inhibition was calculated using the following formula: \% Inhibition $=100 \%$ x $(1-$ (mean RLU of test sample - mean RLU of vehicle control)/(mean RLU of EC80 control - mean RLU of vehicle control). For the orphan max panel, \% agonist activity was calculated as $100 \%$ x (mean of test sample - mean of vehicle control)/mean of vehicle control.

gpcrMAX and NHR - Agonist mode calculation: To determine if a compound is potentially acting as an agonist to activate the receptor and induce arrestin recruitment the following factors should be considered: Is the \% activity $>30 \%$ ? If so, is the compound mean RLU >Baseline RLU + 3 x Baseline SD.

gpcrMAX and NHR - Antagonist mode: Inhibition of GPCR activation by a compound acting as an antagonist of ligand binding results in a decrease in $\beta$-arrestin recruitment to the target GPCR. The NHR panel measures agonist interactions during a 6-h period and antagonist are preincubated for $1 \mathrm{~h}$ prior to agonist challenge. To determine if a compound is potentially acting as an antagonist to inhibit receptor activation the following factors should be considered: Is the \% inhibition $>35 \%$, if so, is the compound mean RLU $<$ EC 80 RLU - 3 x EC80 SD.

orphanMAX - Agonist mode: Activation of Orphan GPCR by a compound acting as an agonist will result in an increase in $\beta$-arrestin recruitment to the target orphan GPCR. To determine if a compound is potentially acting as an agonist 
to activate an orphan receptor and induce arrestin recruitment the following factor should be considered: Is the \% activity $>50 \%$. If so, is the compound mean RLU >Baseline RLU + 3 $\mathrm{x}$ Baseline SD.

TriCEPS technology. This technology from Dualsystems Biotech AG (Zurich, Switzerland) was implemented to detect PRP-1 receptor or interacting partners. Specific cell surface protein receptors are involved in the drug, peptide ligand mediated physiological responses. The TriCEPS method is based on the Ligand-based receptor capture (LRC) technology where special reagent can be coupled to a ligand of interest, which allows to capture the ligand when bound to corresponding receptors. One can picture TriCEPS with three arms: one that binds to amino group containing ligands, a second for the ligand-based capture of glycosylated and a third one with biotin tag for purifying receptor peptides to be analyzed by quantitative mass spectrometry (MS). Specific receptors for the ligand of interest are identified through quantitative comparison of the identified peptides with a sample generated by a control probe with known (e.g., insulin) receptor.

TriCEPS protocol: Ligand coupling: This procedure implemented processing of ligand and the identification of receptor candidates (3 ligand and 3 control samples, $300 \mu \mathrm{g}$ control ligand or $300 \mu \mathrm{g}$ ligand of interest to $120 \mu \mathrm{l}$ of $25 \mathrm{mM}$ HEPES pH 8.2, $1.5 \mu \mathrm{l}(150 \mu \mathrm{g})$ TriCEPS v.3 was added to both reactions and mixed immediately by pipetting up and down using a $200 \mu \mathrm{l}$ pipette, then incubated at $20^{\circ} \mathrm{C}$ under gentle agitation (350 rpm) in a ThermoMixer for $90 \mathrm{~min}$. Cell preparation and oxidation $1.2 \times 10^{8}$ cells were utilized for the experiment in triplicates. Cells were centrifuged at $300 \mathrm{x}$ g for $5 \mathrm{~min}$ at $4^{\circ} \mathrm{C}$, then were resuspended in $49 \mathrm{ml} \mathrm{LRC} \mathrm{buffer}$. The oxidation agent $1 \mathrm{ml}$ ( $75 \mathrm{mM}$ sodium metaperiodate) were added to a final concentration of $1.5 \mathrm{mM}$ metaperiodate, followed by incubation for $15 \mathrm{~min}$ at $4^{\circ} \mathrm{C}$. The mild oxidant sodium metaperiodate generates aldehydes from carbohydrates that link to the proteins of cell surface. When the ligand binds to the receptor, the hydrazine group formed a bond with the aldehyde for protein labeling.

Mass spectrometry. The LRC-TriCEPS samples were analyzed on a Thermo LTQ Orbitrap XL spectrometer. The samples were processed in data dependent acquisition mode in a 90-min gradient with $10 \mathrm{~cm} \mathrm{C18}$ packed column. The statistical ANOVA model was applied to the six remaining samples in the CaptiRec dataset. With models of Gaussian distribution the system tests each protein for differential abundance in all pairwise comparisons of ligand and control samples and calculates P-values. P-values are undergoing multiple comparisons to control the experiment-wide false discovery rate (FDR). Then, this adjusted $\mathrm{P}$-value from each individual protein is plotted against the magnitude of the fold enrichment between the two experimental conditions. The receptor candidate space is defined based on the criteria where the area in the volcano plot that is limited by an enrichment factor of $\geq 4$-fold and an FDR-adjusted $\mathrm{P} \leq 0.01$.

RT2 qPCR primer assays. These custom designed assays by Qiagen (Valencia, CA, USA) served as sensitive gene expression profiling tool for real-time PCR analyses. Assay utilized
RT2 SYBR-Green qPCR Master Mixes. Mature RNA isolated using RNA extraction according to the manufacturer's instructions. RNA quality was determined using a spectrophotometer and was reverse transcribed using a cDNA conversion. The cDNA in combination with RT2 SYBR-Green qPCR Master Mix (cat. no. 330529) was used with RT2 qPCR assays. Ct values were uploaded on web portal at http:// www.qiagen. com/geneglobe. Samples were assigned to control and test groups. $\mathrm{Ct}$ values were normalized based on a manual selection of reference genes. The data analysis web portal calculates fold change/regulation using $\Delta \Delta \mathrm{Ct}$ method, in which $\Delta \mathrm{Ct}$ is calculated between gene of interest (GOI) and an average of housekeeping genes (HKG) followed by $\Delta \Delta \mathrm{Ct}$ calculations $[\Delta \mathrm{Ct}$ (experiment $)-\Delta \mathrm{Ct}($ control) $]$. Fold change is then calculated using the $2^{-\Delta \Delta \mathrm{Ct}}$ formula.

\section{Results}

PRP-1 receptors are not $G$ protein coupled, neither nuclear nor orphan receptors. The search for PRP-1 binding partners started with DiscoverX platform of $G$ protein coupled receptors, (GPCR) in agonist, (Table I) and antagonist modes (Table II). There was no indication that PRP-1 was G protein coupled, neither that this peptide was agonist for orphan receptors (Table III) or agonist/antagonist for nuclear receptor in nhrMax panels (Table IV). MUC5B was identified as PRP-1 receptor binding partner in human chondrosarcoma JJ012 cell line using Ligand-receptor capture technology. We proceeded further in the attempt to identify binding partners for PRP-1 using TriCEPS Ligand-receptor capture (LRC) technology from Dualsystems Biotech AG (45). LRC was used to identify novel ligand-receptor interactions. After the TriCEPS coupled ligand (PRP-1) bound to its targets in or at the cell membrane the second arm of TriCEPS coupled to the glycans of that target receptor. The third arm of TriCEPS was used to isolate the proteins that are bound to TriCEPS (Fig. 1A). In the next step the isolated proteins were subjected to a trypsin digest. The resulting peptides of the digest were identified and quantified using liquid chromatography, tandem mass spectrometry (LC-MS/MS) $(45,46)$. Then, the quantified peptides from the control reaction (transferrin as ligand) were compared to the ligand of interest (PRP-1) reaction (labelled in the volcano plot as peptide). The proteins that were 4-fold enriched in one of the treatments compared to the other treatments were considered as the binding partners of the ligand used. When the cells were treated with TriCEPS coupled transferrin, the transferrin receptor protein (TFR1) was enriched (left side of the volcano plot), whereas in the ligand of interest treated samples the MUC5B was enriched. Thus, MUC5B was identified as receptor for PRP-1 (Fig. 1B). The data of the experiment was presented in biological triplicates. The P-value obtained for every protein was plotted against the $\log 2$ of the magnitude of the fold enrichment. The space for positive control receptors and high-confidence receptor candidates was designated and visualized based on (fold-change $>4$ ) significant enrichment (adjusted $\mathrm{P}<0.01$ ). True positive receptor candidates that contain only few tryptic peptides can be enriched substantially but will rarely get adjusted $\mathrm{P}<0.01$. For the final selection of receptor candidates for follow-up investigations, all proteins in the receptor space should be viewed based on the following 
Table I. PRP-1 effect on GPCR receptors (agonist mode).

\begin{tabular}{|c|c|c|c|c|c|c|c|c|c|}
\hline GPCR ID & $\begin{array}{l}\text { Assay } \\
\text { mode }\end{array}$ & $\begin{array}{l}\text { Conc } \\
(\mu \mathrm{M})\end{array}$ & $\begin{array}{l}\text { Mean } \\
\text { RLU }\end{array}$ & $\begin{array}{c}\% \\
\text { Activity }\end{array}$ & GPCR ID & $\begin{array}{l}\text { Assay } \\
\text { mode }\end{array}$ & $\begin{array}{l}\text { Conc } \\
(\mu \mathrm{M})\end{array}$ & $\begin{array}{l}\text { Mean } \\
\text { RLU }\end{array}$ & $\begin{array}{c}\% \\
\text { Activity }\end{array}$ \\
\hline ADCYAP1R1 & Agonist & 6 & 271200 & 1 & CXCR3 & Agonist & 6 & 387900 & 1 \\
\hline ADORA3 & Agonist & 6 & 213700 & 1 & CXCR4 & Agonist & 6 & 72500 & 2 \\
\hline ADRA1B & Agonist & 6 & 372900 & 1 & CXCR5 & Agonist & 6 & 230900 & 1 \\
\hline ADRA2A & Agonist & 6 & 312500 & 0 & CXCR6 & Agonist & 6 & 27700 & 2 \\
\hline ADRA2B & Agonist & 6 & 315400 & 4 & CXCR7 & Agonist & 6 & 194500 & 0 \\
\hline ADRA2C & Agonist & 6 & 296300 & 0 & DRD1 & Agonist & 6 & 73000 & 0 \\
\hline ADRB 1 & Agonist & 6 & 184300 & 1 & DRD2L & Agonist & 6 & 83500 & 0 \\
\hline ADRB2 & Agonist & 6 & 18800 & 3 & DRD2S & Agonist & 6 & 247200 & 0 \\
\hline AGTR1 & Agonist & 6 & 424900 & 2 & DRD3 & Agonist & 6 & 414700 & 2 \\
\hline AGTRL1 & Agonist & 6 & 429300 & 1 & DRD4 & Agonist & 6 & 22800 & 3 \\
\hline AVPR1A & Agonist & 6 & 23600 & 0 & DRD5 & Agonist & 6 & 21000 & 1 \\
\hline AVPR1B & Agonist & 6 & 35200 & 0 & $\mathrm{EBI} 2$ & Agonist & 6 & 150100 & 0 \\
\hline AVPR2 & Agonist & 6 & 822800 & 0 & EDG1 & Agonist & 6 & 165500 & 0 \\
\hline BDKRB1 & Agonist & 6 & 30100 & 1 & EDG3 & Agonist & 6 & 877900 & 0 \\
\hline BDKRB2 & Agonist & 6 & 663600 & 0 & EDG4 & Agonist & 6 & 234300 & 4 \\
\hline BRS3 & Agonist & 6 & 209300 & 0 & EDG5 & Agonist & 6 & 174300 & 1 \\
\hline C3AR1 & Agonist & 6 & 55900 & 0 & EDG6 & Agonist & 6 & 574100 & -2 \\
\hline C5AR1 & Agonist & 6 & 119400 & 0 & EDG7 & Agonist & 6 & 154400 & 0 \\
\hline C5L2 & Agonist & 6 & 164800 & 0 & EDNRA & Agonist & 6 & 38500 & 0 \\
\hline CALCR & Agonist & 6 & 42500 & 1 & EDNRB & Agonist & 6 & 68900 & 0 \\
\hline CALCRL-RAMP1 & Agonist & 6 & 92800 & 0 & F2R & Agonist & 6 & 470700 & -2 \\
\hline CALCRL-RAMP2 & Agonist & 6 & 219200 & 1 & F2RL1 & Agonist & 6 & 566200 & 0 \\
\hline CALCRL-RAMP3 & Agonist & 6 & 425200 & 0 & F2RL3 & Agonist & 6 & 909900 & -1 \\
\hline CALCR-RAMP2 & Agonist & 6 & 139500 & 2 & FFAR1 & Agonist & 6 & 560800 & 3 \\
\hline CALCR-RAMP3 & Agonist & 6 & 28600 & 7 & FPR1 & Agonist & 6 & 1133900 & 4 \\
\hline CCKAR & Agonist & 6 & 44600 & 0 & FPRL1 & Agonist & 6 & 63900 & 0 \\
\hline CCKBR & Agonist & 6 & 894800 & 0 & FSHR & Agonist & 6 & 197900 & -2 \\
\hline CCR 10 & Agonist & 6 & 93400 & 0 & GALR1 & Agonist & 6 & 263400 & 1 \\
\hline CCR1 & Agonist & 6 & 540700 & 7 & GALR2 & Agonist & 6 & 307700 & 1 \\
\hline CCR2 & Agonist & 6 & 67000 & 0 & GCGR & Agonist & 6 & 295600 & 0 \\
\hline CCR3 & Agonist & 6 & 272100 & 2 & GHSR & Agonist & 6 & 524600 & 2 \\
\hline CCR4 & Agonist & 6 & 180300 & 0 & GIPR & Agonist & 6 & 17500 & -1 \\
\hline CCR5 & Agonist & 6 & 89800 & 0 & GLP1R & Agonist & 6 & 123500 & 0 \\
\hline CCR6 & Agonist & 6 & 141000 & 0 & GLP2R & Agonist & 6 & 101400 & 1 \\
\hline CCR7 & Agonist & 6 & 766200 & 1 & GPR1 & Agonist & 6 & 58400 & 0 \\
\hline CCR8 & Agonist & 6 & 35900 & 0 & GPR103 & Agonist & 6 & 45100 & 2 \\
\hline CCR9 & Agonist & 6 & 119300 & 1 & GPR109A & Agonist & 6 & 458200 & 4 \\
\hline CHRM1 & Agonist & 6 & 1181100 & 1 & GPR109B & Agonist & 6 & 410400 & 1 \\
\hline CHRM2 & Agonist & 6 & 54600 & 1 & GPR119 & Agonist & 6 & 289300 & 3 \\
\hline CHRM3 & Agonist & 6 & 166300 & 2 & GPR120 & Agonist & 6 & 27800 & 1 \\
\hline CHRM4 & Agonist & 6 & 787900 & 16 & GPR35 & Agonist & 6 & 287100 & 1 \\
\hline CHRM5 & Agonist & 6 & 2995100 & 5 & GPR92 & Agonist & 6 & 257600 & 1 \\
\hline CMKLR1 & Agonist & 6 & 81900 & 0 & GRPR & Agonist & 6 & 39000 & 0 \\
\hline CNR1 & Agonist & 6 & 80000 & 0 & HCRTR1 & Agonist & 6 & 45600 & 0 \\
\hline CNR2 & Agonist & 6 & 315400 & -2 & HCRTR2 & Agonist & 6 & 69900 & 0 \\
\hline CRHR1 & Agonist & 6 & 361400 & 1 & HRH1 & Agonist & 6 & 345600 & 1 \\
\hline CRHR2 & Agonist & 6 & 161100 & 0 & HRH2 & Agonist & 6 & 91300 & 1 \\
\hline CRTH2 & Agonist & 6 & 172600 & 0 & HRH3 & Agonist & 6 & 47100 & 2 \\
\hline CX3CR1 & Agonist & 6 & 342700 & 1 & HRH4 & Agonist & 6 & 910300 & 4 \\
\hline CXCR1 & Agonist & 6 & 219900 & 0 & HTR1A & Agonist & 6 & 879000 & 0 \\
\hline CXCR2 & Agonist & 6 & 165200 & 1 & HTR1B & Agonist & 6 & 1214900 & -4 \\
\hline
\end{tabular}

Table I. Continued. 
Table I. Continued.

\begin{tabular}{|c|c|c|c|c|c|c|c|c|c|}
\hline GPCR ID & $\begin{array}{l}\text { Assay } \\
\text { mode }\end{array}$ & $\begin{array}{l}\text { Conc } \\
(\mu \mathrm{M})\end{array}$ & $\begin{array}{l}\text { Mean } \\
\text { RLU }\end{array}$ & $\begin{array}{c}\% \\
\text { Activity }\end{array}$ & GPCR ID & $\begin{array}{l}\text { Assay } \\
\text { mode }\end{array}$ & $\begin{array}{l}\text { Conc } \\
(\mu \mathrm{M})\end{array}$ & $\begin{array}{l}\text { Mean } \\
\text { RLU }\end{array}$ & $\begin{array}{c}\% \\
\text { Activity }\end{array}$ \\
\hline HTR1E & Agonist & 6 & 2963300 & 3 & RXFP3 & Agonist & 6 & 149000 & 6 \\
\hline HTR1F & Agonist & 6 & 345900 & 2 & SCTR & Agonist & 6 & 502600 & 1 \\
\hline HTR2A & Agonist & 6 & 455100 & 1 & SSTR1 & Agonist & 6 & 15000 & -3 \\
\hline HTR2C & Agonist & 6 & 921600 & 1 & SSTR2 & Agonist & 6 & 11800 & 0 \\
\hline HTR5A & Agonist & 6 & 990000 & 0 & SSTR3 & Agonist & 6 & 82000 & 1 \\
\hline KISS1R & Agonist & 6 & 45800 & 1 & SSTR5 & Agonist & 6 & 176900 & 1 \\
\hline LHCGR & Agonist & 6 & 24700 & 0 & TACR1 & Agonist & 6 & 702100 & 1 \\
\hline LTB4R & Agonist & 6 & 187300 & 1 & TACR2 & Agonist & 6 & 415100 & 1 \\
\hline MC1R & Agonist & 6 & 17000 & -2 & TACR3 & Agonist & 6 & 145800 & 0 \\
\hline MC3R & Agonist & 6 & 25100 & 3 & TBXA2R & Agonist & 6 & 203300 & 1 \\
\hline MC4R & Agonist & 6 & 25900 & -1 & TRHR & Agonist & 6 & 27600 & 1 \\
\hline MC5R & Agonist & 6 & 54900 & 2 & TSHR(L) & Agonist & 6 & 9600 & 4 \\
\hline MCHR1 & Agonist & 6 & 140300 & 1 & UTR2 & Agonist & 6 & 31200 & 3 \\
\hline MCHR2 & Agonist & 6 & 62800 & 1 & VIPR1 & Agonist & 6 & 399800 & 0 \\
\hline MLNR & Agonist & 6 & 227800 & 1 & VIPR2 & Agonist & 6 & 342300 & 1 \\
\hline
\end{tabular}

MRGPRX2

MTNR1A

NMBR

NMU1R

NPBWR1

NPBWR2

NPFFR1

NPSR1B

NPY1R

NPY2R

NTSR1

OPRD1

OPRK1

OPRL1

OPRM1

OXER1

OXTR

P2RY1

P2RY11

P2RY12

P2RY2

P2RY4

P2RY6

PPYR1

PRLHR

PROKR1

PROKR2

PTAFR

PTGER2

PTGER3

PTGER4

PTGFR

PTGIR

PTHR1

PTHR2
Agonist

Agonist

Agonist

Agonist

Agonist

Agonist

Agonist

Agonist

Agonist

Agonist

Agonist

Agonist

Agonist

Agonist

Agonist

Agonist

Agonist

Agonist

Agonist

Agonist

Agonist

Agonist

Agonist

Agonist

Agonist

Agonist

Agonist

Agonist

Agonist

Agonist

Agonist

Agonist

Agonist

Agonist
Agonist
355800

79100

62800

98100

69600

169400

131100

89900

106100

362000

313400

91200

36400

229600

137000

86900

25800

123800

68900

250500

384500

397000

324200

34900

35900

49600

15700

480900

30800

246700

95700

16400

135100

129100

123100
Table I. Continued.

parameters: proteins that were increased $>4$ times $(\log 2=2$ on the $\mathrm{x}$-axis) with adjusted $\mathrm{P}<0.01 \quad[-\log (0.01)=2]$ were considered to be in the receptor space (white). The protter figure (Fig. 1C) usually displays peptides belonging to the ligand's receptor as being enriched (shown in highlighted stripes) compared with the control sample (no ligand). Protter is an interactive tool for protein data analysis (47). The experimental results with MUC5B ELISA confirmed the binding, PRP-1 at $1 \mu \mathrm{g} / \mathrm{ml}$ detected MUC5B presence at $440 \mathrm{ng} / \mathrm{ml}$ in the cell lysates of human JJ012 chondrosarcoma cells (Fig. 1D). Toll like receptors TLR1/2 and TLR6 were identified by western blot as binding interaction partners with PRP-1 in human chondrosarcoma JJ012 cell line lysates. Polyacrylamide gel electrophoresis, immunoblot results indicated that PRP-1 caused strong upregulation of TLR1 and TLR2 in comparison to untreated control. TLR3 expression was present but weak and data is not shown. TLR4 and TLR5 were expressed, but PRP-1 did not have any effect (Fig. 2). TLR6 protein expression was also increased in dose-dependent manner in PRP-1 treated samples. TLR7 was not expressed at all in the cell line, whereas TLR8, 9 and 10 were expressed but there was no indication of PRP-1 effect (Fig. 2). Thus, TLR1/2 and TLR6 were identified as interacting binding partners for PRP-1. Fig. 2 depicts the PRP- 1 action on the protein expression of the adaptors TICAM1 (TRIF) and TICAM2 (TRAM). PRP-1 upregulated in dose-dependent manner the adaptor TICAM2 but not TICAM1. Toll like receptors TLR1/2 and TLR6 and MUC5B were detected with PRP-1 in the nucleus of human chondrosarcoma cells by immunocytochemistry. Since the experiments with immunoblot and TriCEPS indicated that cell surface receptors TLR1/2, TLR6 and gel forming mucin MUC5B were the binding partners for PRP-1, the immunocytochemistry experiments followed next; not only to prove PRP-1 endogenous presence in chondrosarcoma, but also its cellular colocalization with the binding partners. The images are displayed in Fig. 3. PRP-1 antibody, isolated from rabbit 
A

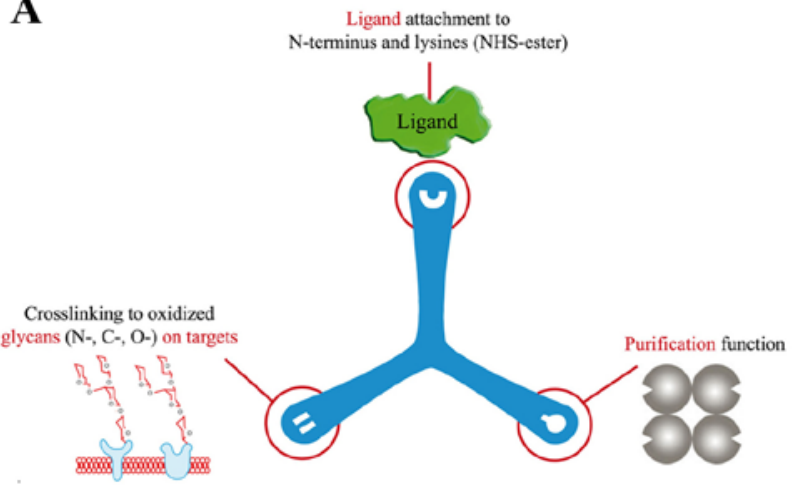

B

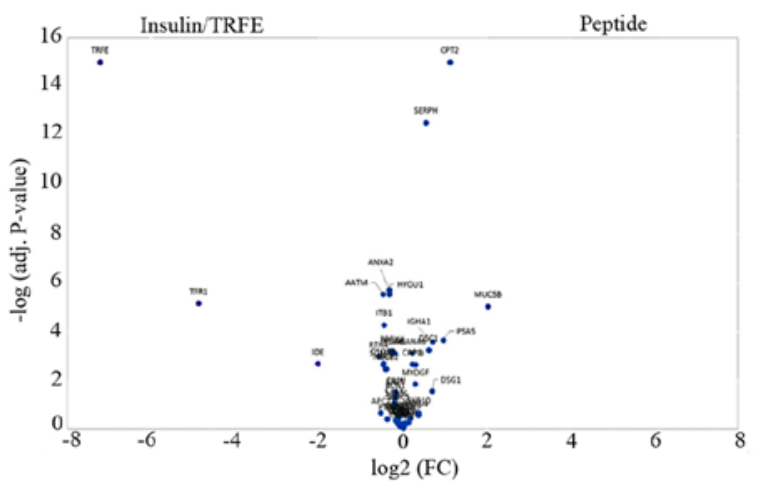

C

MUC5B Human

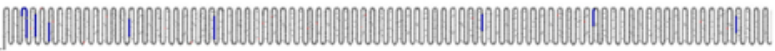

D

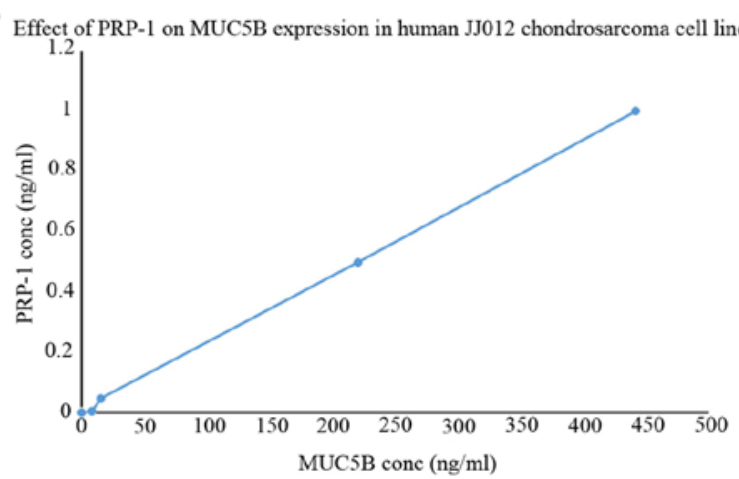

Figure 1. Identification of PRP-1 receptor binding protein MUC5B by Ligand-receptor capture technology (LRC) and human MUC5B ELISA in JJ012 chondrosarcoma cell line. (A) Ligand-receptor capture technology (LRC). Three orthogonal functionalities in TRICEPS-one arm binding an amino group containing ligands, a second arm that captures ligand with glycosylated receptors and the third arm has a biotin tag for purifying receptor peptides to be detected by quantitative mass spectrometry (MS). (B) Volcano plot. LRC-TriCEPS volcano plot compares the proteins that are enriched in the control samples (left side, $x$-axes Value -2 till -8) include enriched TRF1 $=$ Transferrin receptor (true positive) and borderline IDE, insulindegrading enzyme compared to the ligand of interest, (PRP-1) samples (on the right) in human chondrosarcoma cells. On the right side of the volcano plot (x-axes Value +2 till +8 ) the target MUC5B of ligand of interest (PRP-1) is depicted. On the $\mathrm{x}$-axis $\log 2$ of the fold change of the quantified protein comparing the samples of the ligand of interest with the control. On the $y$-axis the -log (adj. P-value) as the experiment was performed in triplicates. (C) Protter. In the protter picture the tryptic peptides (highlighted) that are identified by LC-MS/MS measurement for MUC5B. (D) Human MUC5B ELISA in the cell lysates of human JJ012 chondrosarcoma cells. PRP-1 at $1 \mu \mathrm{g} / \mathrm{ml}$ detected MUC5B presence at $440 \mathrm{ng} / \mathrm{ml}$ (D).

Table II. PRP-1 effect on GPCR receptors (antagonist mode).

\begin{tabular}{|c|c|c|c|c|}
\hline GPCR ID & $\begin{array}{l}\text { Assay } \\
\text { mode }\end{array}$ & $\begin{array}{l}\text { Conc } \\
(\mu \mathrm{M})\end{array}$ & $\begin{array}{l}\text { Mean } \\
\text { RLU }\end{array}$ & $\begin{array}{c}\% \\
\text { Inhibition }\end{array}$ \\
\hline ADCYAP1R1 & Antagonist & 6 & 1676100 & -6 \\
\hline ADORA3 & Antagonist & 6 & 891300 & -3 \\
\hline ADRA1B & Antagonist & 6 & 2076200 & 0 \\
\hline ADRA2A & Antagonist & 6 & 1075700 & 0 \\
\hline ADRA2B & Antagonist & 6 & 856100 & 2 \\
\hline ADRA2C & Antagonist & 6 & 1511200 & -4 \\
\hline ADRB1 & Antagonist & 6 & 674600 & -5 \\
\hline ADRB2 & Antagonist & 6 & 179900 & -3 \\
\hline AGTR1 & Antagonist & 6 & 2568500 & 0 \\
\hline AGTRL1 & Antagonist & 6 & 2263600 & 0 \\
\hline AVPR1A & Antagonist & 6 & 789300 & -1 \\
\hline AVPR1B & Antagonist & 6 & 258900 & -2 \\
\hline AVPR2 & Antagonist & 6 & 3487000 & 0 \\
\hline BDKRB1 & Antagonist & 6 & 225900 & -8 \\
\hline BDKRB2 & Antagonist & 6 & 4293900 & 5 \\
\hline BRS3 & Antagonist & 6 & 1248800 & 4 \\
\hline C3AR1 & Antagonist & 6 & 1933800 & -2 \\
\hline C5AR1 & Antagonist & 6 & 2029300 & 3 \\
\hline $\mathrm{C} 5 \mathrm{~L} 2$ & Antagonist & 6 & 547000 & -5 \\
\hline CALCR & Antagonist & 6 & 358200 & 1 \\
\hline CALCRL-RAMP1 & Antagonist & 6 & 1395000 & 4 \\
\hline CALCRL-RAMP2 & Antagonist & 6 & 892100 & -1 \\
\hline CALCRL-RAMP3 & Antagonist & 6 & 2293600 & 1 \\
\hline CALCR-RAMP2 & Antagonist & 6 & 698200 & 0 \\
\hline CALCR-RAMP3 & Antagonist & 6 & 59000 & -8 \\
\hline CCKAR & Antagonist & 6 & 1490300 & -3 \\
\hline CCKBR & Antagonist & 6 & 3697600 & -3 \\
\hline CCR10 & Antagonist & 6 & 1295800 & -3 \\
\hline CCR1 & Antagonist & 6 & 1214200 & -3 \\
\hline CCR2 & Antagonist & 6 & 1380800 & -3 \\
\hline CCR3 & Antagonist & 6 & 1136200 & -3 \\
\hline CCR4 & Antagonist & 6 & 2075100 & 2 \\
\hline CCR5 & Antagonist & 6 & 2359300 & -2 \\
\hline CCR6 & Antagonist & 6 & 1487700 & 2 \\
\hline CCR7 & Antagonist & 6 & 3413600 & -2 \\
\hline CCR8 & Antagonist & 6 & 1376000 & -4 \\
\hline CCR9 & Antagonist & 6 & 1538300 & -6 \\
\hline CHRM1 & Antagonist & 6 & 2892100 & -12 \\
\hline CHRM2 & Antagonist & 6 & 540500 & -6 \\
\hline CHRM3 & Antagonist & 6 & 1187400 & -6 \\
\hline CHRM4 & Antagonist & 6 & 1390200 & -18 \\
\hline CHRM5 & Antagonist & 6 & 4585200 & -4 \\
\hline CMKLR1 & Antagonist & 6 & 3258400 & -2 \\
\hline CNR1 & Antagonist & 6 & 377300 & 2 \\
\hline CNR2 & Antagonist & 6 & 580500 & 5 \\
\hline CRHR1 & Antagonist & 6 & 4103800 & 1 \\
\hline CRHR2 & Antagonist & 6 & 2968600 & -2 \\
\hline CRTH2 & Antagonist & 6 & 1149200 & -8 \\
\hline CX3CR1 & Antagonist & 6 & 3207000 & 2 \\
\hline CXCR1 & Antagonist & 6 & 3818300 & -1 \\
\hline CXCR2 & Antagonist & 6 & 565700 & -3 \\
\hline
\end{tabular}


Table II. Continued.

\begin{tabular}{|c|c|c|c|c|c|c|c|c|c|}
\hline GPCR ID & $\begin{array}{l}\text { Assay } \\
\text { mode }\end{array}$ & $\begin{array}{l}\text { Conc } \\
(\mu \mathrm{M})\end{array}$ & $\begin{array}{l}\text { Mean } \\
\text { RLU }\end{array}$ & $\begin{array}{c}\% \\
\text { Inhibition }\end{array}$ & GPCR ID & $\begin{array}{l}\text { Assay } \\
\text { mode }\end{array}$ & $\begin{array}{l}\text { Conc } \\
(\mu \mathrm{M})\end{array}$ & $\begin{array}{l}\text { Mean } \\
\text { RLU }\end{array}$ & $\begin{array}{c}\% \\
\text { Inhibition }\end{array}$ \\
\hline CXCR3 & Antagonist & 6 & 1392600 & -1 & HTR1E & Antagonist & 6 & 5487000 & 5 \\
\hline CXCR4 & Antagonist & 6 & 139700 & 2 & HTR1F & Antagonist & 6 & 982500 & 2 \\
\hline CXCR5 & Antagonist & 6 & 1098600 & -8 & HTR2A & Antagonist & 6 & 3103200 & -5 \\
\hline CXCR6 & Antagonist & 6 & 101400 & -6 & HTR2C & Antagonist & 6 & 4188400 & -3 \\
\hline CXCR7 & Antagonist & 6 & 2856200 & -2 & HTR5A & Antagonist & 6 & 4536500 & 0 \\
\hline DRD1 & Antagonist & 6 & 696300 & -5 & KISS1R & Antagonist & 6 & 270900 & 3 \\
\hline DRD2L & Antagonist & 6 & 393800 & 2 & LHCGR & Antagonist & 6 & 144000 & -15 \\
\hline DRD2S & Antagonist & 6 & 1242000 & 6 & LTB4R & Antagonist & 6 & 1844800 & 0 \\
\hline DRD3 & Antagonist & 6 & 1263000 & -15 & MC1R & Antagonist & 6 & 69300 & -2 \\
\hline DRD4 & Antagonist & 6 & 65500 & -2 & MC3R & Antagonist & 6 & 153200 & -6 \\
\hline DRD5 & Antagonist & 6 & 149600 & -8 & MC4R & Antagonist & 6 & 128200 & -6 \\
\hline $\mathrm{EBI} 2$ & Antagonist & 6 & 2425000 & -1 & MC5R & Antagonist & 6 & 179900 & -5 \\
\hline EDG1 & Antagonist & 6 & 936700 & 0 & MCHR1 & Antagonist & 6 & 1023000 & -4 \\
\hline EDG3 & Antagonist & 6 & 4548500 & 1 & MCHR2 & Antagonist & 6 & 530900 & -3 \\
\hline EDG4 & Antagonist & 6 & 657500 & 5 & MLNR & Antagonist & 6 & 2032800 & -7 \\
\hline EDG5 & Antagonist & 6 & 2180100 & -8 & MRGPRX1 & Antagonist & 6 & 3890200 & -2 \\
\hline EDG6 & Antagonist & 6 & 1169200 & 4 & MRGPRX2 & Antagonist & 6 & 1945500 & -8 \\
\hline EDG7 & Antagonist & 6 & 1432500 & -3 & MTNR1A & Antagonist & 6 & 241200 & -9 \\
\hline EDNRA & Antagonist & 6 & 953300 & 0 & NMBR & Antagonist & 6 & 720100 & -5 \\
\hline EDNRB & Antagonist & 6 & 1248000 & -1 & NMU1R & Antagonist & 6 & 985900 & -3 \\
\hline F2R & Antagonist & 6 & 1612200 & -16 & NPBWR1 & Antagonist & 6 & 188200 & 0 \\
\hline F2RL1 & Antagonist & 6 & 3638100 & 3 & NPBWR2 & Antagonist & 6 & 1070300 & -3 \\
\hline F2RL3 & Antagonist & 6 & 3027600 & -1 & NPFFR1 & Antagonist & 6 & 290800 & -3 \\
\hline FFAR1 & Antagonist & 6 & 1070500 & 0 & NPSR1B & Antagonist & 6 & 699900 & 0 \\
\hline FPR1 & Antagonist & 6 & 3077200 & -4 & NPY1R & Antagonist & 6 & 973600 & 4 \\
\hline FPRL1 & Antagonist & 6 & 2991600 & -2 & NPY2R & Antagonist & 6 & 3477300 & -2 \\
\hline FSHR & Antagonist & 6 & 621700 & -2 & NTSR1 & Antagonist & 6 & 2192400 & -1 \\
\hline GALR1 & Antagonist & 6 & 1759100 & -4 & OPRD1 & Antagonist & 6 & 795800 & -2 \\
\hline GALR2 & Antagonist & 6 & 1686800 & -11 & OPRK1 & Antagonist & 6 & 215800 & -12 \\
\hline GCGR & Antagonist & 6 & 3115100 & -4 & OPRL1 & Antagonist & 6 & 1062000 & -7 \\
\hline GHSR & Antagonist & 6 & 2068100 & -6 & OPRM1 & Antagonist & 6 & 2828200 & -2 \\
\hline GIPR & Antagonist & 6 & 79600 & -24 & OXER1 & Antagonist & 6 & 246400 & -16 \\
\hline GLP1R & Antagonist & 6 & 1983100 & -9 & OXTR & Antagonist & 6 & 540000 & 1 \\
\hline GLP2R & Antagonist & 6 & 727800 & -11 & P2RY1 & Antagonist & 6 & 530600 & 1 \\
\hline GPR1 & Antagonist & 6 & 1076400 & -5 & P2RY11 & Antagonist & 6 & 484300 & -12 \\
\hline GPR103 & Antagonist & 6 & 103800 & 6 & P2RY 12 & Antagonist & 6 & 699600 & 8 \\
\hline GPR109A & Antagonist & 6 & 1141200 & -4 & P2RY2 & Antagonist & 6 & 1093000 & -4 \\
\hline GPR109B & Antagonist & 6 & 2871700 & -6 & P2RY4 & Antagonist & 6 & 1323200 & 0 \\
\hline GPR119 & Antagonist & 6 & 521500 & -1 & P2RY6 & Antagonist & 6 & 1825600 & 3 \\
\hline GPR120 & Antagonist & 6 & 130400 & -6 & PPYR1 & Antagonist & 6 & 276600 & -4 \\
\hline GPR35 & Antagonist & 6 & 910400 & -6 & PRLHR & Antagonist & 6 & 122100 & -3 \\
\hline GPR92 & Antagonist & 6 & 854500 & 12 & PROKR1 & Antagonist & 6 & 499800 & -2 \\
\hline GRPR & Antagonist & 6 & 1570000 & -7 & PROKR2 & Antagonist & 6 & 111500 & 8 \\
\hline HCRTR1 & Antagonist & 6 & 3242300 & 0 & PTAFR & Antagonist & 6 & 3532600 & -8 \\
\hline HCRTR2 & Antagonist & 6 & 2611400 & -1 & PTGER2 & Antagonist & 6 & 72100 & -11 \\
\hline HRH1 & Antagonist & 6 & 1912200 & 0 & PTGER3 & Antagonist & 6 & 967100 & -2 \\
\hline HRH2 & Antagonist & 6 & 347800 & 1 & PTGER4 & Antagonist & 6 & 852400 & 4 \\
\hline HRH3 & Antagonist & 6 & 180200 & -6 & PTGFR & Antagonist & 6 & 453000 & 1 \\
\hline HRH4 & Antagonist & 6 & 2264500 & -9 & PTGIR & Antagonist & 6 & 380600 & -2 \\
\hline HTR 1A & Antagonist & 6 & 2576600 & -5 & PTHR1 & Antagonist & 6 & 2941200 & -2 \\
\hline HTR1B & Antagonist & 6 & 2334400 & 4 & PTHR2 & Antagonist & 6 & 2882300 & -1 \\
\hline
\end{tabular}

Table II. Continued. 
Table II. Continued.

\begin{tabular}{llclc}
\hline GPCR ID & $\begin{array}{c}\text { Assay } \\
\text { mode }\end{array}$ & $\begin{array}{c}\text { Conc } \\
(\mu \mathrm{M})\end{array}$ & $\begin{array}{c}\text { Mean } \\
\text { RLU }\end{array}$ & $\begin{array}{c}\% \\
\text { Inhibition }\end{array}$ \\
\hline RXFP3 & Antagonist & 6 & 330200 & -3 \\
SCTR & Antagonist & 6 & 3424900 & -2 \\
SSTR1 & Antagonist & 6 & 38300 & -14 \\
SSTR2 & Antagonist & 6 & 797000 & -11 \\
SSTR3 & Antagonist & 6 & 771000 & -5 \\
SSTR5 & Antagonist & 6 & 1327400 & -11 \\
TACR1 & Antagonist & 6 & 4862800 & -2 \\
TACR2 & Antagonist & 6 & 2331100 & 0 \\
TACR3 & Antagonist & 6 & 2745900 & -1 \\
TBXA2R & Antagonist & 6 & 1032900 & -10 \\
TRHR & Antagonist & 6 & 301600 & -5 \\
TSHR(L) & Antagonist & 6 & 83000 & -4 \\
UTR2 & Antagonist & 6 & 156000 & -7 \\
VIPR1 & Antagonist & 6 & 3344300 & -9 \\
VIPR2 & Antagonist & 6 & 3604300 & -3 \\
\hline
\end{tabular}

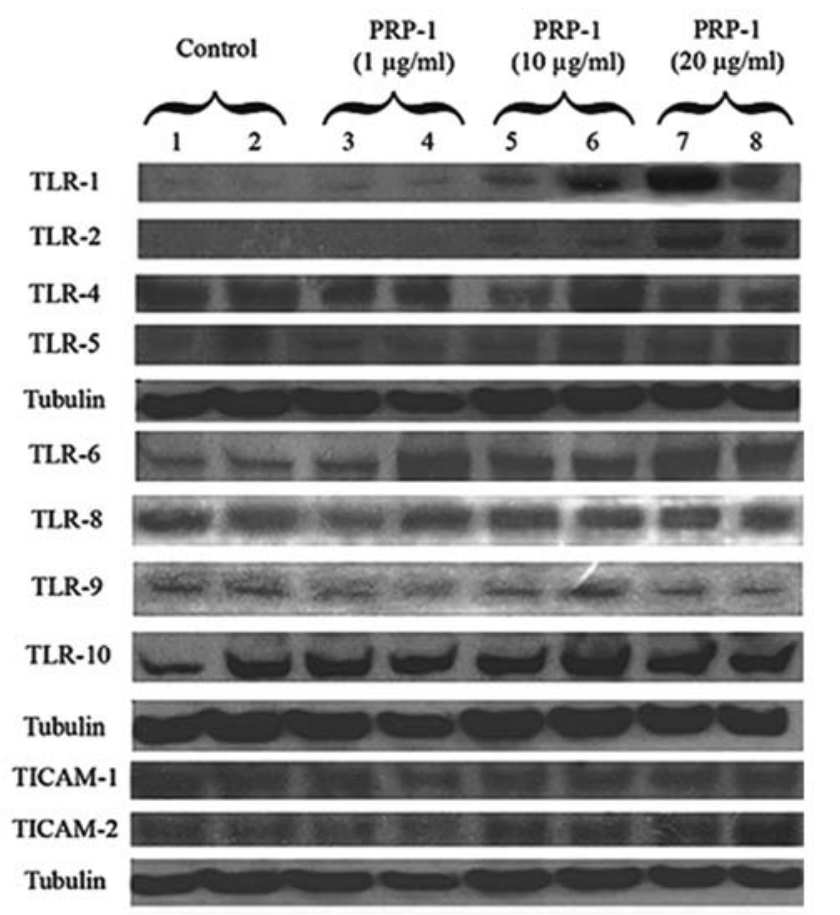

Figure 2. PRP-1 effect on TLR receptors and adaptor proteins in human chondrosarcoma JJ012 cell line. PRP-1 upregulated protein expression of TLR1 and TLR2 in dose-dependent manner in human JJ012 chondrosarcoma cell lysates. TLR3 expression was very weak and the data is not shown. TLR4, TLR5 proteins were expressed but PRP-1 did not have any effect. Tubulin was used as loading control. The bands were detected for TLR1, TLR2, TLR4 and TLR5 and tubulin at 120,119, 130, 90 and $50 \mathrm{kDa}$, correspondingly. PRP-1 upregulated protein expression of TLR6 in dose-dependent manner in human JJ012 chondrosarcoma cell lysates. TLR7 was not expressed in this cell line at all. TLR8, 9 and 10 were expressed but no effect of PRP-1 was observed. Tubulin was used as housekeeping control. The bands were detected for TLR6, TLR8, TLR9, TLR10 and tubulin at 100, 86, 100, 120 and $50 \mathrm{kDa}$, correspondingly. PRP-1 upregulated TICAM2 (TRAM) adaptor protein in dose-response manner but did not have any effect on TICAM1 (TRIF) adaptor protein in human JJ012 chondrosarcoma cell line. Tubulin was used as loading control. The bands were detected for TICAM1, TICAM2 and tubulin.
Table III. PRP-1 effect on orphan receptors (agonist mode).

\begin{tabular}{|c|c|c|c|c|}
\hline GPCR ID & $\begin{array}{l}\text { Assay } \\
\text { mode }\end{array}$ & $\begin{array}{l}\text { Conc } \\
(\mu \mathrm{M})\end{array}$ & $\begin{array}{l}\text { Mean } \\
\text { RLU }\end{array}$ & $\begin{array}{c}\% \\
\text { Inhibition }\end{array}$ \\
\hline ADCYAP1R1 & Antagonist & 6 & 1676100 & -6 \\
\hline ADORA3 & Antagonist & 6 & 891300 & -3 \\
\hline ADRA1B & Antagonist & 6 & 2076200 & 0 \\
\hline ADRA2A & Antagonist & 6 & 1075700 & 0 \\
\hline ADRA2B & Antagonist & 6 & 856100 & 2 \\
\hline ADRA2C & Antagonist & 6 & 1511200 & -4 \\
\hline ADRB1 & Antagonist & 6 & 674600 & -5 \\
\hline ADRB2 & Antagonist & 6 & 179900 & -3 \\
\hline AGTR1 & Antagonist & 6 & 2568500 & 0 \\
\hline AGTRL1 & Antagonist & 6 & 2263600 & 0 \\
\hline AVPR1A & Antagonist & 6 & 789300 & -1 \\
\hline AVPR1B & Antagonist & 6 & 258900 & -2 \\
\hline AVPR2 & Antagonist & 6 & 3487000 & 0 \\
\hline BDKRB1 & Antagonist & 6 & 225900 & -8 \\
\hline BDKRB2 & Antagonist & 6 & 4293900 & 5 \\
\hline BRS3 & Antagonist & 6 & 1248800 & 4 \\
\hline C3AR1 & Antagonist & 6 & 1933800 & -2 \\
\hline C5AR1 & Antagonist & 6 & 2029300 & 3 \\
\hline C5L2 & Antagonist & 6 & 547000 & -5 \\
\hline CALCR & Antagonist & 6 & 358200 & 1 \\
\hline CALCRL-RAMP1 & Antagonist & 6 & 1395000 & 4 \\
\hline CALCRL-RAMP2 & Antagonist & 6 & 892100 & -1 \\
\hline CALCRL-RAMP3 & Antagonist & 6 & 2293600 & 1 \\
\hline CALCR-RAMP2 & Antagonist & 6 & 698200 & 0 \\
\hline CALCR-RAMP3 & Antagonist & 6 & 59000 & -8 \\
\hline CCKAR & Antagonist & 6 & 1490300 & -3 \\
\hline CCKBR & Antagonist & 6 & 3697600 & -3 \\
\hline CCR10 & Antagonist & 6 & 1295800 & -3 \\
\hline CCR1 & Antagonist & 6 & 1214200 & -3 \\
\hline CCR2 & Antagonist & 6 & 1380800 & -3 \\
\hline CCR3 & Antagonist & 6 & 1136200 & -3 \\
\hline CCR4 & Antagonist & 6 & 2075100 & 2 \\
\hline CCR5 & Antagonist & 6 & 2359300 & -2 \\
\hline CCR6 & Antagonist & 6 & 1487700 & 2 \\
\hline CCR7 & Antagonist & 6 & 3413600 & -2 \\
\hline CCR8 & Antagonist & 6 & 1376000 & -4 \\
\hline CCR9 & Antagonist & 6 & 1538300 & -6 \\
\hline CHRM1 & Antagonist & 6 & 2892100 & -12 \\
\hline CHRM2 & Antagonist & 6 & 540500 & -6 \\
\hline CHRM3 & Antagonist & 6 & 1187400 & -6 \\
\hline CHRM4 & Antagonist & 6 & 1390200 & -18 \\
\hline CHRM5 & Antagonist & 6 & 4585200 & -4 \\
\hline CMKLR1 & Antagonist & 6 & 3258400 & -2 \\
\hline CNR1 & Antagonist & 6 & 377300 & 2 \\
\hline CNR2 & Antagonist & 6 & 580500 & 5 \\
\hline CRHR1 & Antagonist & 6 & 4103800 & 1 \\
\hline CRHR2 & Antagonist & 6 & 2968600 & -2 \\
\hline CRTH2 & Antagonist & 6 & 1149200 & -8 \\
\hline CX3CR1 & Antagonist & 6 & 3207000 & 2 \\
\hline CXCR1 & Antagonist & 6 & 3818300 & -1 \\
\hline CXCR2 & Antagonist & 6 & 565700 & -3 \\
\hline
\end{tabular}


Table III. Continued.

\begin{tabular}{|c|c|c|c|c|c|c|c|c|c|}
\hline GPCR ID & $\begin{array}{l}\text { Assay } \\
\text { mode }\end{array}$ & $\begin{array}{l}\text { Conc } \\
(\mu \mathrm{M})\end{array}$ & $\begin{array}{l}\text { Mean } \\
\text { RLU }\end{array}$ & $\begin{array}{c}\% \\
\text { Inhibition }\end{array}$ & GPCR ID & $\begin{array}{l}\text { Assay } \\
\text { mode }\end{array}$ & $\begin{array}{l}\text { Conc } \\
(\mu \mathrm{M})\end{array}$ & $\begin{array}{l}\text { Mean } \\
\text { RLU }\end{array}$ & $\begin{array}{c}\% \\
\text { Inhibition }\end{array}$ \\
\hline CXCR3 & Antagonist & 6 & 1392600 & -1 & HTR1E & Antagonist & 6 & 5487000 & 5 \\
\hline CXCR4 & Antagonist & 6 & 139700 & 2 & HTR1F & Antagonist & 6 & 982500 & 2 \\
\hline CXCR5 & Antagonist & 6 & 1098600 & -8 & HTR2A & Antagonist & 6 & 3103200 & -5 \\
\hline CXCR6 & Antagonist & 6 & 101400 & -6 & HTR2C & Antagonist & 6 & 4188400 & -3 \\
\hline CXCR7 & Antagonist & 6 & 2856200 & -2 & HTR5A & Antagonist & 6 & 4536500 & 0 \\
\hline DRD1 & Antagonist & 6 & 696300 & -5 & KISS1R & Antagonist & 6 & 270900 & 3 \\
\hline DRD2L & Antagonist & 6 & 393800 & 2 & LHCGR & Antagonist & 6 & 144000 & -15 \\
\hline DRD2S & Antagonist & 6 & 1242000 & 6 & LTB4R & Antagonist & 6 & 1844800 & 0 \\
\hline DRD3 & Antagonist & 6 & 1263000 & -15 & MC1R & Antagonist & 6 & 69300 & -2 \\
\hline DRD4 & Antagonist & 6 & 65500 & -2 & MC3R & Antagonist & 6 & 153200 & -6 \\
\hline DRD5 & Antagonist & 6 & 149600 & -8 & MC4R & Antagonist & 6 & 128200 & -6 \\
\hline EBI2 & Antagonist & 6 & 2425000 & -1 & MC5R & Antagonist & 6 & 179900 & -5 \\
\hline EDG1 & Antagonist & 6 & 936700 & 0 & MCHR1 & Antagonist & 6 & 1023000 & -4 \\
\hline EDG3 & Antagonist & 6 & 4548500 & 1 & MCHR2 & Antagonist & 6 & 530900 & -3 \\
\hline EDG4 & Antagonist & 6 & 657500 & 5 & MLNR & Antagonist & 6 & 2032800 & -7 \\
\hline EDG5 & Antagonist & 6 & 2180100 & -8 & MRGPRX1 & Antagonist & 6 & 3890200 & -2 \\
\hline EDG6 & Antagonist & 6 & 1169200 & 4 & MRGPRX2 & Antagonist & 6 & 1945500 & -8 \\
\hline EDG7 & Antagonist & 6 & 1432500 & -3 & MTNR1A & Antagonist & 6 & 241200 & -9 \\
\hline EDNRA & Antagonist & 6 & 953300 & 0 & NMBR & Antagonist & 6 & 720100 & -5 \\
\hline EDNRB & Antagonist & 6 & 1248000 & -1 & NMU1R & Antagonist & 6 & 985900 & -3 \\
\hline F2R & Antagonist & 6 & 1612200 & -16 & NPBWR1 & Antagonist & 6 & 188200 & 0 \\
\hline F2RL1 & Antagonist & 6 & 3638100 & 3 & NPBWR2 & Antagonist & 6 & 1070300 & -3 \\
\hline F2RL3 & Antagonist & 6 & 3027600 & -1 & NPFFR1 & Antagonist & 6 & 290800 & -3 \\
\hline FFAR1 & Antagonist & 6 & 1070500 & 0 & NPSR1B & Antagonist & 6 & 699900 & 0 \\
\hline FPR1 & Antagonist & 6 & 3077200 & -4 & NPY1R & Antagonist & 6 & 973600 & 4 \\
\hline FPRL1 & Antagonist & 6 & 2991600 & -2 & NPY2R & Antagonist & 6 & 3477300 & -2 \\
\hline FSHR & Antagonist & 6 & 621700 & -2 & NTSR1 & Antagonist & 6 & 2192400 & -1 \\
\hline GALR1 & Antagonist & 6 & 1759100 & -4 & OPRD1 & Antagonist & 6 & 795800 & -2 \\
\hline GALR2 & Antagonist & 6 & 1686800 & -11 & OPRK1 & Antagonist & 6 & 215800 & -12 \\
\hline GCGR & Antagonist & 6 & 3115100 & -4 & OPRL1 & Antagonist & 6 & 1062000 & -7 \\
\hline GHSR & Antagonist & 6 & 2068100 & -6 & OPRM1 & Antagonist & 6 & 2828200 & -2 \\
\hline GIPR & Antagonist & 6 & 79600 & -24 & OXER1 & Antagonist & 6 & 246400 & -16 \\
\hline GLP1R & Antagonist & 6 & 1983100 & -9 & OXTR & Antagonist & 6 & 540000 & 1 \\
\hline GLP2R & Antagonist & 6 & 727800 & -11 & P2RY1 & Antagonist & 6 & 530600 & 1 \\
\hline GPR1 & Antagonist & 6 & 1076400 & -5 & P2RY11 & Antagonist & 6 & 484300 & -12 \\
\hline GPR103 & Antagonist & 6 & 103800 & 6 & P2RY 12 & Antagonist & 6 & 699600 & 8 \\
\hline GPR109A & Antagonist & 6 & 1141200 & -4 & P2RY2 & Antagonist & 6 & 1093000 & -4 \\
\hline GPR109B & Antagonist & 6 & 2871700 & -6 & P2RY4 & Antagonist & 6 & 1323200 & 0 \\
\hline GPR119 & Antagonist & 6 & 521500 & -1 & P2RY6 & Antagonist & 6 & 1825600 & 3 \\
\hline GPR120 & Antagonist & 6 & 130400 & -6 & PPYR1 & Antagonist & 6 & 276600 & -4 \\
\hline GPR35 & Antagonist & 6 & 910400 & -6 & PRLHR & Antagonist & 6 & 122100 & -3 \\
\hline GPR92 & Antagonist & 6 & 854500 & 12 & PROKR1 & Antagonist & 6 & 499800 & -2 \\
\hline GRPR & Antagonist & 6 & 1570000 & -7 & PROKR2 & Antagonist & 6 & 111500 & 8 \\
\hline HCRTR1 & Antagonist & 6 & 3242300 & 0 & PTAFR & Antagonist & 6 & 3532600 & -8 \\
\hline HCRTR2 & Antagonist & 6 & 2611400 & -1 & PTGER2 & Antagonist & 6 & 72100 & -11 \\
\hline HRH1 & Antagonist & 6 & 1912200 & 0 & PTGER3 & Antagonist & 6 & 967100 & -2 \\
\hline HRH2 & Antagonist & 6 & 347800 & 1 & PTGER4 & Antagonist & 6 & 852400 & 4 \\
\hline HRH3 & Antagonist & 6 & 180200 & -6 & PTGFR & Antagonist & 6 & 453000 & 1 \\
\hline HRH4 & Antagonist & 6 & 2264500 & -9 & PTGIR & Antagonist & 6 & 380600 & -2 \\
\hline HTR1A & Antagonist & 6 & 2576600 & -5 & PTHR1 & Antagonist & 6 & 2941200 & -2 \\
\hline HTR1B & Antagonist & 6 & 2334400 & 4 & PTHR2 & Antagonist & 6 & 2882300 & -1 \\
\hline
\end{tabular}

Table III. Continued. 
Table III. Continued.

\begin{tabular}{|c|c|c|c|c|c|c|c|c|c|}
\hline GPCR ID & $\begin{array}{l}\text { Assay } \\
\text { mode }\end{array}$ & $\begin{array}{l}\text { Conc } \\
(\mu \mathrm{M})\end{array}$ & $\begin{array}{l}\text { Mean } \\
\text { RLU }\end{array}$ & $\begin{array}{c}\% \\
\text { Inhibition }\end{array}$ & GPCR ID & $\begin{array}{l}\text { Assay } \\
\text { mode }\end{array}$ & $\begin{array}{l}\text { Conc } \\
(\mu \mathrm{M})\end{array}$ & $\begin{array}{l}\text { Mean } \\
\text { RLU }\end{array}$ & $\begin{array}{c}\% \\
\text { Inhibition }\end{array}$ \\
\hline RXFP3 & Antagonist & 6 & 330200 & -3 & CCR8 & Agonist & 6 & 35900 & 0 \\
\hline SCTR & Antagonist & 6 & 3424900 & -2 & CCR9 & Agonist & 6 & 119300 & 1 \\
\hline SSTR1 & Antagonist & 6 & 38300 & -14 & CHRM1 & Agonist & 6 & 1181100 & 1 \\
\hline SSTR2 & Antagonist & 6 & 797000 & -11 & CHRM2 & Agonist & 6 & 54600 & 1 \\
\hline SSTR3 & Antagonist & 6 & 771000 & -5 & CHRM3 & Agonist & 6 & 166300 & 2 \\
\hline SSTR5 & Antagonist & 6 & 1327400 & -11 & CHRM4 & Agonist & 6 & 787900 & 16 \\
\hline TACR1 & Antagonist & 6 & 4862800 & -2 & CHRM5 & Agonist & 6 & 2995100 & 5 \\
\hline TACR2 & Antagonist & 6 & 2331100 & 0 & CMKLR1 & Agonist & 6 & 81900 & 0 \\
\hline TACR3 & Antagonist & 6 & 2745900 & -1 & CNR1 & Agonist & 6 & 80000 & 0 \\
\hline TBXA2R & Antagonist & 6 & 1032900 & -10 & CNR2 & Agonist & 6 & 315400 & -2 \\
\hline TRHR & Antagonist & 6 & 301600 & -5 & CRHR1 & Agonist & 6 & 361400 & 1 \\
\hline TSHR(L) & Antagonist & 6 & 83000 & -4 & CRHR2 & Agonist & 6 & 161100 & 0 \\
\hline UTR2 & Antagonist & 6 & 156000 & -7 & CRTH2 & Agonist & 6 & 172600 & 0 \\
\hline VIPR1 & Antagonist & 6 & 3344300 & -9 & CX3CR 1 & Agonist & 6 & 342700 & 1 \\
\hline VIPR2 & Antagonist & 6 & 3604300 & -3 & CXCR1 & Agonist & 6 & 219900 & 0 \\
\hline ADCYAP1R1 & Agonist & 6 & 271200 & 1 & CXCR2 & Agonist & 6 & 165200 & 1 \\
\hline ADORA3 & Agonist & 6 & 213700 & 1 & CXCR3 & Agonist & 6 & 387900 & 1 \\
\hline ADRA1B & Agonist & 6 & 372900 & 1 & CXCR4 & Agonist & 6 & 72500 & 2 \\
\hline ADRA2A & Agonist & 6 & 312500 & 0 & CXCR5 & Agonist & 6 & 230900 & 1 \\
\hline ADRA2B & Agonist & 6 & 315400 & 4 & CXCR6 & Agonist & 6 & 27700 & 2 \\
\hline ADRA2C & Agonist & 6 & 296300 & 0 & CXCR7 & Agonist & 6 & 194500 & 0 \\
\hline ADRB 1 & Agonist & 6 & 184300 & 1 & DRD1 & Agonist & 6 & 73000 & 0 \\
\hline ADRB2 & Agonist & 6 & 18800 & 3 & DRD2L & Agonist & 6 & 83500 & 0 \\
\hline AGTR1 & Agonist & 6 & 424900 & 2 & DRD2S & Agonist & 6 & 247200 & 0 \\
\hline AGTRL1 & Agonist & 6 & 429300 & 1 & DRD3 & Agonist & 6 & 414700 & 2 \\
\hline AVPR1A & Agonist & 6 & 23600 & 0 & DRD4 & Agonist & 6 & 22800 & 3 \\
\hline AVPR1B & Agonist & 6 & 35200 & 0 & DRD5 & Agonist & 6 & 21000 & 1 \\
\hline AVPR2 & Agonist & 6 & 822800 & 0 & $\mathrm{EBI} 2$ & Agonist & 6 & 150100 & 0 \\
\hline BDKRB1 & Agonist & 6 & 30100 & 1 & EDG1 & Agonist & 6 & 165500 & 0 \\
\hline BDKRB2 & Agonist & 6 & 663600 & 0 & EDG3 & Agonist & 6 & 877900 & 0 \\
\hline BRS3 & Agonist & 6 & 209300 & 0 & EDG4 & Agonist & 6 & 234300 & 4 \\
\hline C3AR1 & Agonist & 6 & 55900 & 0 & EDG5 & Agonist & 6 & 174300 & 1 \\
\hline C5AR1 & Agonist & 6 & 119400 & 0 & EDG6 & Agonist & 6 & 574100 & -2 \\
\hline C5L2 & Agonist & 6 & 164800 & 0 & EDG7 & Agonist & 6 & 154400 & 0 \\
\hline CALCR & Agonist & 6 & 42500 & $\begin{array}{l}1 \\
0\end{array}$ & EDNRA & Agonist & 6 & 38500 & 0 \\
\hline $\begin{array}{l}\text { CALCRL-RAMP1 } \\
\text { CAI_RI_RAMP? }\end{array}$ & Agonist & 6 & $\begin{array}{l}92800 \\
219200\end{array}$ & $\begin{array}{l}0 \\
1\end{array}$ & EDNRB & Agonist & 6 & 68900 & 0 \\
\hline $\begin{array}{l}\text { CALCRL-RAMP2 } \\
\text { CALCRL-RAMP3 }\end{array}$ & $\begin{array}{l}\text { Agonist } \\
\text { Agonist }\end{array}$ & $\begin{array}{l}6 \\
6\end{array}$ & $\begin{array}{l}219200 \\
425200\end{array}$ & $\begin{array}{l}1 \\
0\end{array}$ & F2R & Agonist & 6 & 470700 & -2 \\
\hline $\begin{array}{l}\text { CALCRL-RAMP3 } \\
\text { CALCR-RAMP2 }\end{array}$ & $\begin{array}{l}\text { Agonist } \\
\text { Agonist }\end{array}$ & $\begin{array}{l}6 \\
6\end{array}$ & $\begin{array}{l}425200 \\
139500\end{array}$ & $\begin{array}{l}0 \\
2\end{array}$ & F2RL1 & Agonist & 6 & 566200 & 0 \\
\hline CALCR-RAMP3 & Agonist & 6 & 28600 & $\begin{array}{l}2 \\
7\end{array}$ & F2RL3 & Agonist & 6 & 909900 & -1 \\
\hline CCKAR & Agonist & 6 & 44600 & 0 & FFAR1 & Agonist & 6 & 560800 & 3 \\
\hline CCKBR & Agonist & 6 & 894800 & 0 & FPR1 & Agonist & 6 & 1133900 & 4 \\
\hline CCR10 & Agonist & 6 & 93400 & 0 & FPRL1 & Agonist & 6 & 63900 & 0 \\
\hline CCR 1 & Agonist & 6 & 540700 & 7 & FSHR & Agonist & 6 & 197900 & -2 \\
\hline CCR2 & Agonist & 6 & 67000 & 0 & GALR1 & Agonist & 6 & 263400 & 1 \\
\hline CCR3 & Agonist & 6 & 272100 & 2 & GALR2 & Agonist & 6 & 307700 & 1 \\
\hline CCR4 & Agonist & 6 & 180300 & 0 & GCGR & Agonist & 6 & 295600 & 0 \\
\hline CCR5 & Agonist & 6 & 89800 & 0 & GHSR & Agonist & 6 & 524600 & 2 \\
\hline CCR6 & Agonist & 6 & 141000 & 0 & GIPR & Agonist & 6 & 17500 & -1 \\
\hline CCR7 & Agonist & 6 & 766200 & 1 & GLP1R & Agonist & 6 & 123500 & 0 \\
\hline
\end{tabular}

Table III. Continued. 
Table IV. PRP-1 activity with nhrMAX panel.

\begin{tabular}{|c|c|c|c|c|c|c|c|}
\hline Assay format & Assay target & Conc $(\mu \mathrm{M})$ & Value 1 & Value 2 & Average value & SD & $\%$ Efficacy \\
\hline Agonist & AR & 6 & 3600 & 3200 & 3400 & 282.84 & -0.3 \\
\hline Antagonist & $\mathrm{AR}$ & 6 & 17200 & 17400 & 17300 & 141.42 & 4.3 \\
\hline Agonist & ERalpha & 6 & 50400 & 50000 & 50200 & 282.84 & 0.6 \\
\hline Antagonist & ERalpha & 6 & 293600 & 288200 & 290900 & 3818.4 & -2.8 \\
\hline Antagonist & ERRalpha & 6 & 65800 & 61200 & 63500 & 3252.7 & -4.7 \\
\hline Inverse agonist & ERRalpha & 6 & 134600 & 120000 & 127300 & 10324 & -7.2 \\
\hline Agonist & FXR & 6 & 4000 & 6200 & 5100 & 1555.6 & 0.9 \\
\hline Antagonist & FXR & 6 & 95400 & 103400 & 99400 & 5656.9 & -4.5 \\
\hline Agonist & GR & 6 & 15200 & 16800 & 16000 & 1131.4 & 0.3 \\
\hline Antagonist & GR & 6 & 999800 & 1086200 & 1043000 & 61094 & -9.7 \\
\hline Agonist & LXRalpha & 6 & 232800 & 216800 & 224800 & 11314 & -0.6 \\
\hline Antagonist & LXRalpha & 6 & 1660000 & 1807600 & 1733800 & 104370 & -10.7 \\
\hline Agonist & LXRbeta & 6 & 311400 & 330200 & 320800 & 13294 & 1.6 \\
\hline Antagonist & LXRbeta & 6 & 1208200 & 1379200 & 1293700 & 120920 & -4 \\
\hline Agonist & MR & 6 & 16200 & 18000 & 17100 & 1272.8 & 0.3 \\
\hline Antagonist & MR & 6 & 295400 & 303800 & 299600 & 5939.7 & -0.7 \\
\hline Agonist & PPARalpha & 6 & 14600 & 15000 & 14800 & 282.84 & 0.9 \\
\hline Antagonist & PPARalpha & 6 & 108400 & 105000 & 106700 & 2404.2 & -3.3 \\
\hline Agonist & PPARdelta & 6 & 1077800 & 1247000 & 1162400 & 119640 & 0.9 \\
\hline Antagonist & PPARdelta & 6 & 3209000 & 2884800 & 3046900 & 229240 & 2.2 \\
\hline Agonist & PPARgamma & 6 & 4400 & 5800 & 5100 & 989.95 & 0.3 \\
\hline Antagonist & PPARgamma & 6 & 29600 & 28400 & 29000 & 848.53 & 6.5 \\
\hline Agonist & PRalpha & 6 & 25800 & 22800 & 24300 & 2121.3 & -1.6 \\
\hline Antagonist & PRalpha & 6 & 185400 & 190400 & 187900 & 3535.5 & -3.1 \\
\hline Agonist & PRbeta & 6 & 3200 & 2400 & 2800 & 565.69 & 1.4 \\
\hline Antagonist & PRbeta & 6 & 28600 & 33600 & 31100 & 3535.5 & -0.6 \\
\hline Agonist & RARalpha & 6 & 29400 & 44800 & 37100 & 10889 & -3.3 \\
\hline Antagonist & RARalpha & 6 & 104000 & 106800 & 105400 & 1979.9 & 14 \\
\hline Agonist & RARbeta & 6 & 263600 & 243600 & 253600 & 14142 & -3.9 \\
\hline Antagonist & RARbeta & 6 & 475000 & 572200 & 523600 & 68731 & -0.5 \\
\hline Agonist & RXRalpha & 6 & 226000 & 230000 & 228000 & 2828.4 & -3.8 \\
\hline Antagonist & RXRalpha & 6 & 851800 & 821400 & 836600 & 21496 & 0 \\
\hline Agonist & RXRgamma & 6 & 367800 & 354200 & 361000 & 9616.7 & -2.7 \\
\hline Antagonist & RXRgamma & 6 & 1266600 & 1310200 & 1288400 & 30830 & -1.2 \\
\hline Agonist & THRalpha & 6 & 43400 & 34600 & 39000 & 6222.5 & -0.2 \\
\hline Antagonist & THRalpha & 6 & 383000 & 415800 & 399400 & 23193 & -4.8 \\
\hline Agonist & THRbeta & 6 & 732400 & 819600 & 776000 & 61660 & 9.3 \\
\hline Antagonist & THRbeta & 6 & 1274000 & 1246600 & 1260300 & 19375 & -5.2 \\
\hline
\end{tabular}

$\mathrm{SD}$, standard deviation.

serum and affinity chromatography purified was labeled with Zenon Alexa Fluor 488 IgG complex (green) and manifested its presence in the nucleus (labeled with DAPI in blue) of the chondrosarcoma cells (Fig. 3A). The green speckles and dots can be seen both inside and outside the nucleus. In the separate experiment without PRP-1 we have demonstrated that MUC5B is present in the nucleus of these cells as well (Fig. 3B). The plasma membrane is seen in red and MUC5B, which was labeled with DyLight 488 is green. The composite image (Fig. 3C) demonstrates nuclear localization of both MUC5B (left panel) and PRP-1 (right panel) in aqua green color on the background of blue nucleus. Fig. 3D illustrates the presence of TLR1 receptor, (labeled in yellow with H\&L DyLight 550) in the nucleus and around it. Fig. 3E depicts colocalization experiment of TLR6 and PRP-1 and whereas it was problematic to show TLR1 and PRP-1 colocalization in the previous figure due to spectral overlaps, here TLR6 receptor nuclear and cytoplasmic localization is demonstrated 

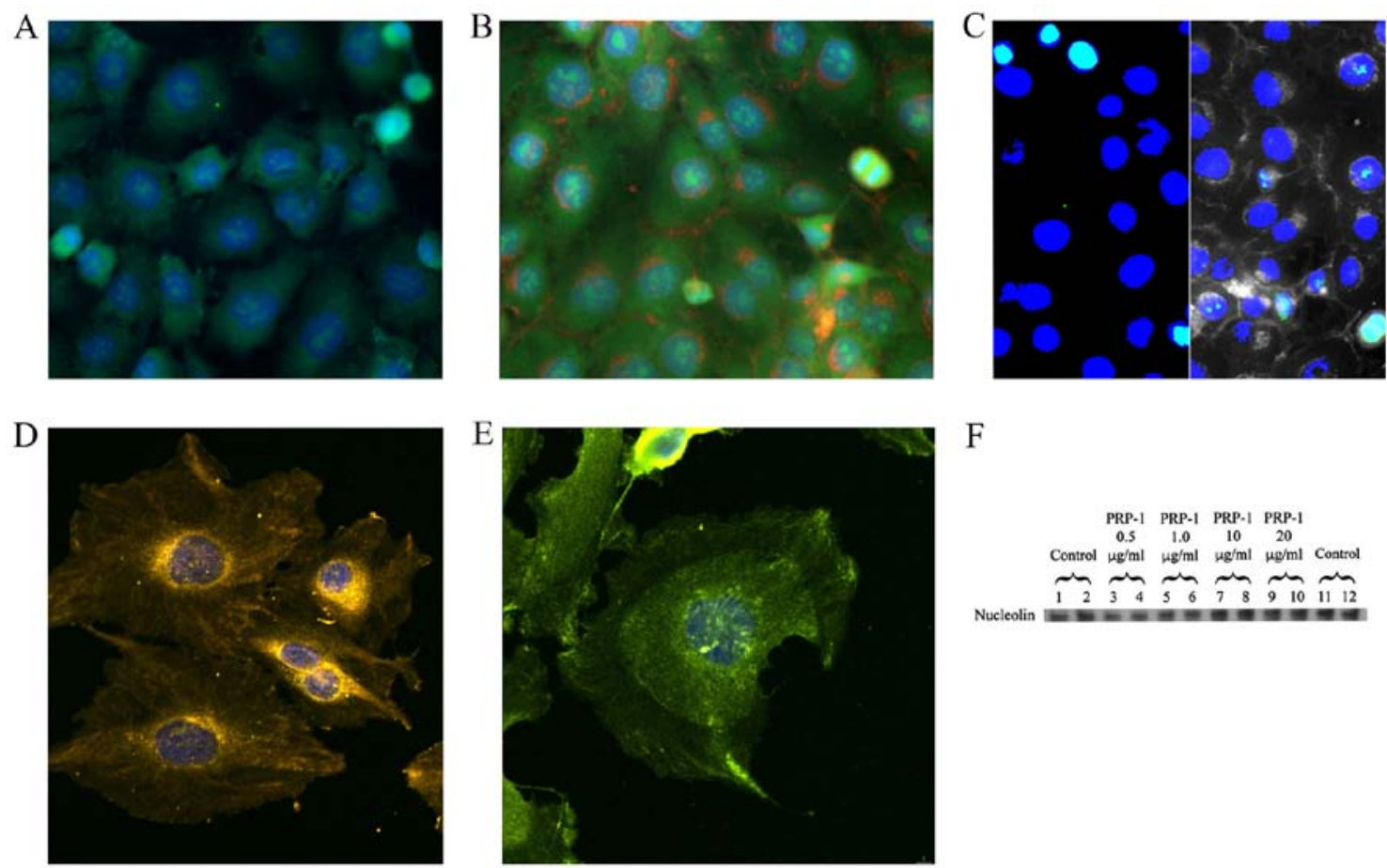

F

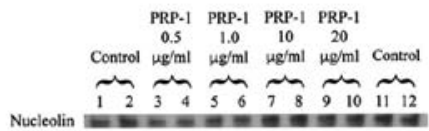

Figure 3. Immunocytochemistry results indicating nuclear localization of PRP-1 and nuclear colocalization with MUC5B, TLR1, TLR6 in human chondrosarcoma JJ012 cell line. (A) PRP-1 antibody localization in nucleus of human chondrosarcoma JJ012 cells. Dark blue color-DAPI was applied for nuclear staining. Zenon Alexa fluor rabbit 488IgG (green) was used for PRP-1 rabbit serum IgG antibody staining. (B) MUC5B receptor localization in the nucleus of human JJ012 chondrosarcoma cells. Alexa Fluor 594 wheat germ agglutinin (WGA) was used to label plasma membrane (red) at 1:200 dilution for $1 \mathrm{~h}$. DAPI (dark blue) stained nucleus at $3 \mu \mathrm{M}$. Rabbit anti-MUC5B was adopted as primary, and green goat anti-rabbit IgG H\&L (DyLight 488) was used as a secondary antibody. (C) Composite image of nuclear localization of MUC5B (left panel) and PRP-1 antibody (right panel) in human JJ012 chondrosarcoma cells. Dark blue color-DAPI was applied for nuclear staining. Zenon Alexa Fluor rabbit 488IgG (green) was used for PRP-1 rabbit serum IgG antibody detection. Rabbit anti-MUC5B was adopted as primary, and green goat anti-rabbit IgG H\&L (DyLight 488) was used as a secondary antibody. (D) TLR1 receptor localization in the cytoplasm and the nucleus in human chondrosarcoma JJ012 cells. TLR1 rabbit antibody was used as a primary, whereas goat anti-rabbit H\&L (DyLight 550) was applied as the secondary antibody (yellow color). (E) TLR6 receptor nuclear and cytoplasmic colocalization with PRP-1 is demonstrated, H\&L DyLight 550 was used as a secondary antibody (yellow). PRP-1 was stained with Zenon Alexa Fluor 488 IgG (green). (F) Western blot of nucleolin protein expression in human chondrosarcoma cell line. PRP-1 did not have any effect on nucleolin expression, indicating the absence of PRP-1 location in nucleoli. The band corresponded to MW of $77 \mathrm{kDa}$.

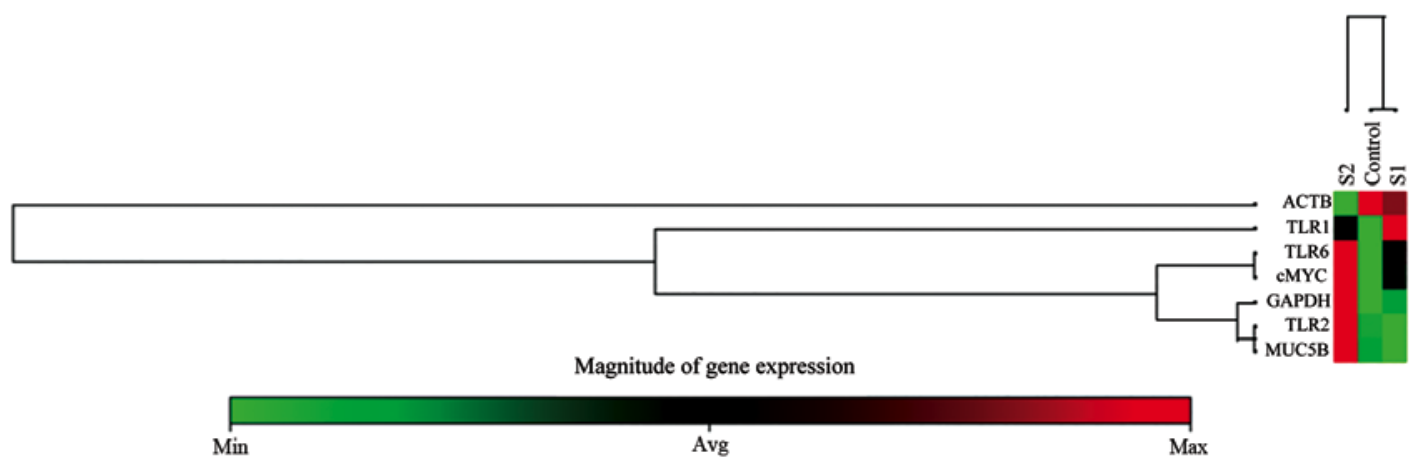

Figure 4. Heat map of gene expression (qRT PCR) upon PRP-1 treatment. The clustrogram performs non-supervised hierarchical clustering of the entire dataset to display a heat map with dendrograms indicating co-regulated genes across groups or individual samples; it represents the average of $\mathrm{Ct}$ values displayed across the genes of each sample. S2 stands for samples treated with $1 \mu \mathrm{g} / \mathrm{ml}$ of PRP-1 and S1 stands for $10 \mu \mathrm{g} / \mathrm{ml}$ of PRP-1. TLR2 and TLR6 were highly expressed in S2, while TLR1 was highly expressed in S1 and moderately in S2 group. c-Myc and MUC5B were highly expressed in S2. GAPDH and ACTB were housekeeping genes.

with PRP-1, which was stained with Zenon Alexa Fluor 488 IgG (green). H\&L DyLight 550 was used as a secondary antibody (yellow) for TLR6. The immunoblot experiment with the nucleolin antibody, marker for nucleoli indicated that PRP-1 was not located in the nucleoli, as no changes in nucleolin protein expression was observed on PRP-1 treatment (Fig. 3F).
RT2 qPCR primer assays show the effect of PRP-1 on gene expression of TLR receptors and MUC5B. RT2 qPCR custom designed primer assays were performed by Qiagen to understand the effect of PRP-1 on gene expression of TLR receptors and MUC5B. Mature RNA was isolated using RNA extraction according to the manufacturer's instructions. RNA 


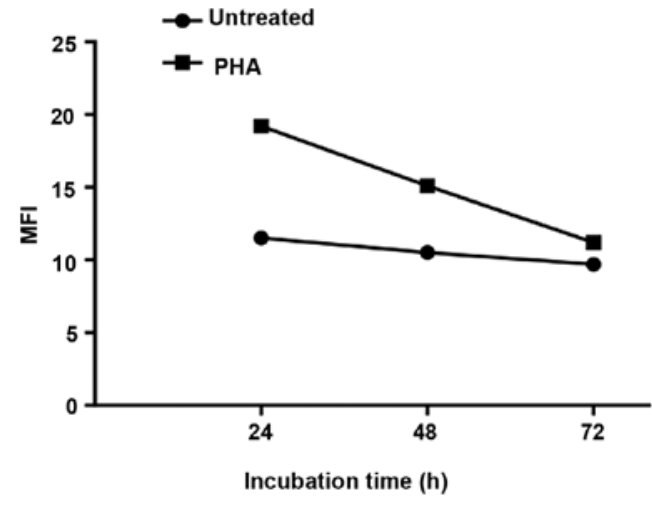

Figure 5. Immunostimulation triggers intracellular PRP-1 synthesis in normal resting and stimulated human peripheral blood lymphocytes. The dynamics of intracellular expression of PRP-1 in PHA-activated lymphocytes indicated that PRP-1 was induced at the early stages of cell activation. On y-axes (MFI)-median fluorescence intensity.

was subjected to spectrophotometrical quality control and then reverse transcribed to cDNA. RT2 SYBR-Green qPCR Master Mix was used with RT2 qPCR assays. In this study, 7 genes (TLR1, TLR2, TLR6, MUC5B, c-Myc and 2 housekeeping genes GAPDH and ACTB) were profiled on three samples with technical triplicates. c-Myc was included, as we wanted to confirm its drastic downregulation after PRP-1 treatment in luciferase assay (4) and western blot experiments, reported earlier (10). The heat map, clustergram of average $\mathrm{Ct}$ values across the gene of each sample, with the magnitude of gene expression scale below, is presented in Fig. 4. As evident from the figure, there is dose-dependent effect of PRP-1 on the expression of the above mentioned genes, except the control housekeeping genes. The TLR1 receptor was well expressed in the cells treated with $10 \mu \mathrm{g} /$ $\mathrm{ml}$, whereas no expression was detected at $1 \mu \mathrm{g} / \mathrm{ml}$ peptide treatment. TLR2, TLR6, MUC5B demonstrated high expression with $1 \mu \mathrm{g} / \mathrm{ml}$ treatment when compared to nontreated control. c-Myc expression went down drastically when treated with $10 \mu \mathrm{g} / \mathrm{ml}$ PRP-1. The data analysis web portal calculated fold change/regulation using $\Delta \Delta \mathrm{Ct}$ method, in which $\Delta \mathrm{Ct}$ is calculated between gene of interest (GOI) and an average of housekeeping genes (HKG) followed by $\Delta \Delta \mathrm{Ct}$ calculations ( $\Delta \mathrm{Ct}$ (experiment) - $\Delta \mathrm{Ct}$ (control). Fold change is then calculated using the $2^{-\Delta \Delta C t}$ formula. The system detected only statistically significant upregulation $(\mathrm{P}<0.0001)$ of TLR2 for the samples treated with $1 \mu \mathrm{g} / \mathrm{ml}$ PRP-1, with 5.26fold upregulation when calculated with the $\Delta \Delta \mathrm{Ct}$.

\section{Discussion}

Metastatic chondrosarcoma is fatal because of metastatic spread and absence of the effective therapies. Therefore, search for new approaches is of the utmost importance. PRP-1, inhibits chondrosarcoma cell growth by $>80 \%(4,6)$ it halts cell cycle progression in G1/S transition (6). This mTORC1 inhibitor, cytostatic peptide is potent upregulator of tumor suppressors and inhibitor of oncoproteins and embryonic stem cell markers (7-9). We have demonstrated also that intracellular expression of PRP-1 is associated with the early stages of lymphocyte activation by phytohemagglutinin, (PHA) (Fig. 5).
However, the interacting partners or receptors for this important peptide has not been identified. Using triCEPS (ligand based receptor capture technology), we were able to identify MUC5B, one of the members of mucin family as the receptor for PRP-1. Notably, proline rich proteins in saliva, different from the neuropeptide PRP-1, were found in reported literature to interact with mucins (48). Immunoblot results of this study indicated that TLR1, TLR2 (which are usually dimerized) and TLR6 are binding interaction partners for PRP-1, as their expression increased in dose-response manner upon PRP-1 treatment. Indeed, the link between TLR1/2 and TLR6 was documented in the literature. TLR1 and TLR6 was shown to pair with TLR2 and that interaction was needed for pattern recognition of pathogens $(49,50)$. TLR7 was not expressed in human JJ012 cell line at all, but all the other TLR groups were present. No changes in the expression of TLR10 were observed with PRP-1, although sometimes it was reported that in certain cases TLR10 is able to homodimerize or heterodimerize with TLR1 and TLR2, but its ligand remains unknown (19). We have demonstrated that PRP-1 upregulates the expression of adaptor protein TICAM2 (TRAM) but not of TICAM1 (TRIF). Most TLRs share a common signaling pathway in which myeloid differentiation factor 88 (MyD88) plays a central role (51). It is known also that TLR2 can be TRAM dependent in addition to the MyD88-dependent pathway with certain MyD88 independent exceptions (51). TLR2 is also internalized following ligand binding, but in this case, MyD88-dependent signaling continues from an intracellular location away from the plasma membrane and stimulates type I IFN production through an as yet unknown mechanism (52). Due to the importance of TLR signaling in tumorigenesis, TLR agonists have potential for antitumor therapy (53-57). Both TLR and mucins have important role in host defense mechanism, however, the link between two of them in non-infectious conditions and cancer pathology deserves attention. Understanding connecting crosstalk between two of them will open new avenues for therapeutic intervention. Cancer cells might use the TLR signaling pathways much in the same way to upregulate the expression of MUCs which in turn may also regulate TLR signaling (22). Mucins are a class of major differentially expressed proteins between normal and cancer cells, which makes them a potential target for anticancer therapies. As a class of glycoproteins, MUCs are recognized as potential markers of disease progression or inhibition (58) and are currently investigated as therapeutic targets for cancer (59). Our experimental results indicated the nuclear localization of both MUC5B and TLR1/2. Indeed the evidence of their nuclear translocation was reported in the literature $(24,60)$. Due to the importance of TLR signaling in tumorigenesis, TLR agonists have potential for antitumor therapy (22,54-58).The fact that PRP-1 has receptors of innate immunity explains observed antibacterial properties of PRP (61). The biochemical evidence for the direct interaction of TLRs or MUC5B with endogenous stimulators is limited. There is no doubt that it is of great significance to identify those ligands and elucidate their biological functions, especially if upon their binding with the ligand, the antiproliferative effect in tumor is manifested. The western blot analysis and immunocytochemistry data indicated upregulated protein expression of TLR1, TLR6, MUC5B after the treatment with PRP-1 in JJ012 human chondrosarcoma cell line, the custom 
designed RT2 qPCR primer assays proved that PRP-1 indeed has effect on expression levels of its interacting partner genes as well. However, depending on the method it showed some dose response differences. For example, in case of TLR 2 the protein expression upregulation with 1 and $10 \mu \mathrm{g} / \mathrm{ml}$ PRP-1 was observed in dose-response manner in western blot experiments. However, the heat map and qRT-PCR $\Delta \mathrm{Ct}$ calculations proved that the highest upregulation of TLR 2 expression is taking place at $1 \mu \mathrm{g} / \mathrm{ml}$ (>5-fold upregulation). On the gene expression level, the qRT-PCR did not report significant fold change in $\Delta \mathrm{Ct}$ for TLR1 or TLR6, whereas in western blot experiments we saw obvious upregulation of protein expression for these respective receptors after the dose response treatment with PRP-1. MUC5B on the heat map demonstrated the most upregulation after the treatment with $1 \mu \mathrm{g} / \mathrm{ml}$, which coincided with MUC5B ELISA results, though TriCEPS technology detected MUC5B as binding partner with $10 \mu \mathrm{g} /$ ml PRP-1 treatment. c-Myc results demonstrated downregulation of its gene expression in dose-response manner with PRP-1, being downregulated very strongly at $10 \mu \mathrm{g} / \mathrm{ml}$, which is concordant with our previous results (10). Despite these differences, it is important to mention that most of inhibitory responses caused by PRP-1 treatment on cell growth of tumor cell lines or upregulation of tumor suppressors and downregulation of oncoproteins, were maximally observed when treated with 1-20 $\mu \mathrm{g} / \mathrm{ml}$ PRP-1 range. PRP-1 is a compound naturally produced in the body and the fact it was detected in the nucleus of chondrosarcoma cells and that it upregulated TLR1/2 dimer and TLR6 possibly indicates PRP-1 as an endogenous ligand.

The ability of TLRs to recognize endogenous stimulators appears to be essential to their function in regulating noninfectious (sterile) inflammation. TLR-induced innate immune responses regulate non-infectious sterile inflammation and subsequently, adaptive immune response. The endogenous TLR ligands and their receptors can be localized in different cellular compartments and cannot interact physiologically. However, when the tissue is injured, the passive release of endogenous ligand or its active transport utilizing non-conventional lysosomal route. In the present study, we were able to identify the pattern recognition receptors of adaptive immunity TLR1, TLR2 and TLR6, and secreted mucin MUC5B as binding partners for cytostatic PRP-1 peptide. The mentioned results allow to understand the immunomodulatory, antibacterial effect of PRP-1, reported by our group before $(3,42,61)$. From oncologic standpoint it is important information that immune receptors play antitumorigenic role when bound to PRP-1 ligand.

\section{Acknowledgements}

The present study was supported in part by a gift from the Ratcliffe Foundation to Miami Center of Orthopedic Research and Education. We would like to thank Qiagen Inc., Service Core for the qRT-PCR experiments, the Analytical Imaging Core Facility at DRI/SCCC, University of Miami, which provided immunocytochemistry imaging service. Our thanks to Ms. Maria Boulina for the help and guidance with the imaging. We would like to thanks Dr Paul Helbling and Dr Florian Marty from Dual Systems Biotech (Zurich),
Switzerland, for their productive collaboration and triCEPS methodology experiments.

\section{References}

1. Ozaki T, Hillmann A, Lindner N, Blasius S and Winkelmann W: Metastasis of chondrosarcoma. J Cancer Res Clin Oncol 122: 625-628, 1996

2. Mirra J: Bone Tumors: Clinical, radiologic, and pathologic correlations. Lea and Febiger, Philadelphia, PA, 1989.

3. Galoyan A: Neurochemistry of brain neuroendocrine immune system: Signal molecules. Neurochem Res 25: 1343-1355, 2000.

4. Galoian K, Temple TH and Galoyan A: Cytostatic effect of the hypothalamic cytokine PRP-1 is mediated by mTOR and cMyc inhibition in high grade chondrosarcoma. Neurochem Res 36: 812-818, 2011.

5. Galoian K, Temple HT and Galoyan A: mTORC1 inhibition and ECM-cell adhesion-independent drug resistance via PI3K-AKT and PI3K-RAS-MAPK feedback loops. Tumour Biol 33: 885-890, 2012.

6. Galoian KA, Temple TH and Galoyan A: Cytostatic effect of novel mTOR inhibitor, PRP-1 (galarmin) in MDA 231 (ER-) breast carcinoma cell line. PRP-1 inhibits mesenchymal tumors. Tumour Biol 32: 745-751, 2011.

7. Galoian KA, Guettouche T, Issac B, Qureshi A and Temple HT: Regulation of onco and tumor suppressor MiRNAs by mTORC1 inhibitor PRP-1 in human chondrosarcoma. Tumour Biol 35: 2335-2341, 2014

8. Galoian K, Qureshi A, Wideroff G and Temple HT: Restoration of desmosomal junction protein expression and inhibition of H3K9specific histone demethylase activity by cytostatic proline-rich polypeptide-1 leads to suppression of tumorigenic potential in human chondrosarcoma cells. Mol Clin Oncol 3: 171-178, 2015.

9. Galoian K, Luo S, Qureshi A, Patel P, Price R, Morse AS, Chailyan G, Abrahamyan S and Temple HT: Effect of cytostatic proline rich polypeptide-1 on tumor suppressors of inflammation pathway signaling in chondrosarcoma. Mol Clin Oncol 5: 618-624, 2016 .

10. Galoian K, Qureshi A, D'Ippolito G, Schiller PC, Molinari M, Johnstone AL, Brothers SP, Paz AC and Temple HT: Epigenetic regulation of embryonic stem cell marker miR302C in human chondrosarcoma as determinant of antiproliferative activity of proline-rich polypeptide 1. Int J Oncol 47: 465-472, 2015.

11. Yu L, Wang L and Chen S: Exogenous or endogenous Toll-like receptor ligands: Which is the MVP in tumorigenesis? Cell Mol Life Sci 69: 935-949, 2012.

12. Rakoff-Nahoum S and Medzhitov R: Toll-like receptors and cancer. Nat Rev Cancer 9: 57-63, 2009.

13. Joshi S, Kumar S, Choudhury A, Ponnusamy MP and Batra SK: Altered Mucins (MUC) trafficking in benign and malignant conditions. Oncotarget 5: 7272-7284, 2014.

14. Blasius AL and Beutler B: Intracellular toll-like receptors. Immunity 32: 305-315, 2010.

15. Huang B, Zhao J, Unkeless JC, Feng ZH and Xiong H: TLR signaling by tumor and immune cells: A double-edged sword. Oncogene 27: 218-224, 2008.

16. Apetoh L, Ghiringhelli F, Tesniere A, Obeid M, Ortiz C, Criollo A, Mignot G, Maiuri MC, Ullrich E, Saulnier P, et al: Toll-like receptor 4-dependent contribution of the immune system to anticancer chemotherapy and radiotherapy. Nat Med 13: 1050-1059, 2007

17. Medzhitov R: Origin and physiological roles of inflammation. Nature 454: 428-435, 2008.

18. Seong SY and Matzinger P: Hydrophobicity: An ancient damageassociated molecular pattern that initiates innate immune responses. Nat Rev Immunol 4: 469-478, 2004.

19. Hasan U, Chaffois C, Gaillard C, Saulnier V, Merck E, Tancredi S, Guiet C, Brière F, Vlach J, Lebecque S, et al: Human TLR10 is a functional receptor, expressed by B cells and plasmacytoid dendritic cells, which activates gene transcription through MyD88. J Immunol 174: 2942-2950, 2005.

20. Lowe EL, Crother TR, Rabizadeh S, Hu B, Wang H, Chen S, Shimada K, Wong MH, Michelsen KS and Arditi M: Toll-like receptor 2 signaling protects mice from tumor development in a mouse model of colitis-induced cancer. PLoS One 5: e13027, 2010.

21. Yu L, Wang L and Chen S: Endogenous toll-like receptor ligands and their biological significance. J Cell Mol Med 14: 2592-2603, 2010 . 
22. Tarang S, Kumar S and Batra SK: Mucins and toll-like receptors: Kith and kin in infection and cancer. Cancer Lett 321: 110-119, 2012.

23. Kanzler H, Barrat FJ, Hessel EM and Coffman RL: Therapeutic targeting of innate immunity with Toll-like receptor agonists and antagonists. Nat Med 13: 552-559, 2007.

24. Lakshminarayanan V, Thompson P, Wolfert MA, Buskas T, Bradley JM, Pathangey LB, Madsen CS, Cohen PA, Gendler SJ and Boons GJ: Immune recognition of tumor-associated mucin MUC1 is achieved by a fully synthetic aberrantly glycosylated MUC1 tripartite vaccine. Proc Natl Acad Sci USA 109: 261-266, 2012.

25. Hollingsworth MA and Swanson BJ: Mucins in cancer: Protection and control of the cell surface. Nat Rev Cancer 4: 45-60, 2004

26. Remmers N, Anderson JM, Linde EM, DiMaio DJ, Lazenby AJ, Wandall HH, Mandel U, Clausen H, Yu F and Hollingsworth MA: Aberrant expression of mucin core proteins and o-linked glycans associated with progression of pancreatic cancer. Clin Cancer Res 19: 1981-1993, 2013.

27. Sóñora C, Mazal D, Berois N, Buisine MP, Ubillos L, Varangot M, Barrios E, Carzoglio J, Aubert JP and Osinaga E: Immunohistochemical analysis of MUC5B apomucin expression in breast cancer and non-malignant breast tissues. J Histochem Cytochem 54: 289-299, 2006.

28. Kim YS, Gum J Jr and Brockhausen I: Mucin glycoproteins in neoplasia. Glycoconj J 13: 693-707, 1996.

29. Turner MS, McKolanis JR, Ramanathan RK, Whitcomb DC and Finn OJ: Mucins in gastrointestinal cancers. Cancer Chemother Biol Response Modif 21: 259-274, 2003.

30. Berois N, Varangot M, Sóñora C, Zarantonelli L, Pressa C, Laviña R, Rodríguez JL, Delgado F, Porchet N, Aubert JP, et al: Detection of bone marrow-disseminated breast cancer cells using an RT-PCR assay of MUC5B mRNA. Int J Cancer 103: 550-555, 2003

31. Moniaux N, Andrianifahanana M, Brand RE and Batra SK Multiple roles of mucins in pancreatic cancer, a lethal and challenging malignancy. Br J Cancer 91: 1633-1638, 2004.

32. Andrianifahanana M, Moniaux N and Batra SK: Regulation of mucin expression: Mechanistic aspects and implications for cancer and inflammatory diseases. Biochim Biophys Acta 1765: 189-222, 2006.

33. Kufe DW: Mucins in cancer: Function, prognosis and therapy Nat Rev Cancer 9: 874-885, 2009.

34. Velcich A, Yang W, Heyer J, Fragale A, Nicholas C, Viani S, Kucherlapati R, Lipkin M, Yang K and Augenlicht L: Colorectal cancer in mice genetically deficient in the mucin Muc2. Science 295: 1726-1729, 2002.

35. Van Seuningen I, Perrais M, Pigny P, Porchet N and Aubert JP: Sequence of the 5'-flanking region and promoter activity of the human mucin gene MUC5B in different phenotypes of colon cancer cells. Biochem J 348: 675-686, 2000.

36. Aziz MA, AlOtaibi M, AlAbdulrahman A, AlDrees M and AlAbdulkarim I: Mucin family genes are downregulated in colorectal cancer patients. J Carcinogene Mutagene S10:009. 2014.

37. Wakata K, Tsuchiya T, Tomoshige K, Takagi K, Yamasaki N, Matsumoto K, Miyazaki T, Nanashima A, Whitsett JA, Maeda Y, et al: A favourable prognostic marker for EGFR mutant non-small cell lung cancer: Immunohistochemical analysis of MUC5B BMJ Open 5: e008366, 2015.

38. Roy MG, Livraghi-Butrico A, Fletcher AA, McElwee MM, Evans SE, Boerner RM, Alexander SN, Bellinghausen LK, Song AS, Petrova YM, et al: Muc5b is required for airway defence. Nature 505: 412-416, 2014

39. Vincent A, Perrais M, Desseyn JL, Aubert JP, Pigny P and Van Seuningen I: Epigenetic regulation (DNA methylation, histone modifications) of the $11 \mathrm{p} 15$ mucin genes (MUC2, MUC5AC, MUC5B, MUC6) in epithelial cancer cells. Oncogene 26: 6566-6576, 2007.

40. Macha MA, Krishn SR, Jahan R, Banerjee K, Batra SK and Jain M: Emerging potential of natural products for targeting mucins for therapy against inflammation and cancer. Cancer Treat Rev 41: 277-288, 2015

41. Markossian KA, Gurvits BY and Galoyan AA: Isolation and identification of novel peptides from secretory granules of neurohypophysis. Neurochem Res 16: 22, 1999.
42. Galoyan AA: Brain neurosecretory cytokines: immune response and neuronal survival. Kluwer Academic Plenum Publishers, New York, 2004. https://doi.org/10.1007/978-1-4419-8893-5.

43. Abrahamyan SS, Davtyan TK, Khachatryan AR, Tumasyan NV, Sahakyan IK, Harutyunyan HA, Chailyan SG and Galoyan AA: Quantification of the hypothalamic proline rich polypeptide-1 in rat blood serum. Neurochem J 8: 38-43, 2014.

44. Yan YX, Boldt-Houle DM, Tillotson BP, Gee MA, D'Eon BJ, Chang XJ, Olesen CE and Palmer MA: Cell-based highthroughput screening assay system for monitoring $G$ protein-coupled receptor activation using beta-galactosidase enzyme complementation technology. J Biomol Screen 7: 451-459, 2002.

45. Frei AP, Moest H, Novy K and Wollscheid B: Ligand-based receptor identification on living cells and tissues using TRICEPS. Nat Protoc 8: 1321-1336, 2013.

46. Slavoff SA and Saghatelian A: Discovering ligand-receptor interactions. Nat Biotechnol 30: 959-961, 2012.

47. Omasits U, Ahrens CH, Müller S and Wollscheid B: Protter: Interactive protein feature visualization and integration with experimental proteomic data. Bioinformatics 30: 884-886, 2014

48. Senapati S, Das S and Batra SK: Mucin-interacting proteins: From function to therapeutics. Trends Biochem Sci 35: 236-245, 2010.

49. Ozinsky A, Underhill DM, Fontenot JD, Hajjar AM, Smith KD, Wilson CB, Schroeder L and Aderem A: The repertoire for pattern recognition of pathogens by the innate immune system is defined by cooperation between toll-like receptors. Proc Natl Acad Sci USA 97: 13766-13771, 2000.

50. Janssens S and Beyaert R: Role of Toll-like receptors in pathogen recognition. Clin Microbiol Rev 16: 637-646, 2003.

51. Nilsen N, Nonstad U, Khan N, Knetter CF, Akira S, Sundan A, Espevik T and Lien E: Lipopolysaccharide and double-stranded RNA up-regulate toll-like receptor 2 independently of myeloid differentiation factor 88. J Biol Chem 279: 39727-39735, 2004.

52. Seibert SA, Mex P, Köhler A, Kaufmann SH and Mittrücker HW TLR2-, TLR4- and Myd88-independent acquired humoral and cellular immunity against Salmonella enterica serovar Typhimurium. Immunol Lett 127: 126-134, 2010.

53. Jeung HC, Moon YW, Rha SY, Yoo NC, Roh JK, Noh SH, Min JS, Kim BS and Chung HC: Phase III trial of adjuvant 5-fluorouracil and adriamycin versus 5-fluorouracil, adriamycin, and polyadenylic-polyuridylic acid (poly A:U) for locally advanced gastric cancer after curative surgery: final results of 15-year follow-up. Ann Oncol 19: 520-526, 2008.

54. Smits EL, Ponsaerts P, Berneman ZN and Van Tendeloo VF: The use of TLR7 and TLR8 ligands for the enhancement of cancer immunotherapy. Oncologist 13: 859-875, 2008.

55. Leonard JP, Link BK, Emmanouilides C, Gregory SA, Weisdorf D, Andrey J, Hainsworth J, Sparano JA, Tsai DE, Horning S, et al: Phase I trial of toll-like receptor 9 agonist PF-3512676 with and following rituximab in patients with recurrent indolent and aggressive non Hodgkin's lymphoma. Clin Cancer Res 13: 6168-6174, 2007.

56. Mikulandra M, Pavelic J and Glavan TM: Recent findings on the application of Toll- like receptors agonists in cancer therapy. Curr Med Chem 24: 2011-2032, 2017.

57. Kaczanowska S, Joseph AM and Davila E: TLR agonists: Our best frenemy in cancer immunotherapy. J Leukoc Biol 93: 847-863, 2013.

58. Rachagani S, Torres MP, Moniaux N and Batra SK: Current status of mucins in the diagnosis and therapy of cancer. Biofactors 35: 509-527, 2009

59. Planque N: Nuclear trafficking of secreted factors and cellsurface receptors: New pathways to regulate cell proliferation and differentiation, and involvement in cancers. Cell Commun Signal 4: 7, 2006

60. Huhta H, Helminen O, Lehenkari PP, Saarnio J, Karttunen TJ and Kauppila JH: Toll-like receptors 1, 2, 4 and 6 in esophageal epithelium, Barrett's esophagus, dysplasia and adenocarcinoma. Oncotarget 7: 23658-23667, 2016.

61. Galoyan AA: Brain immune system signal molecules in protection from aerobic and anaerobic infections. In: Advances in Neurobiology. Vol 6: Springer, 2012.

This work is licensed under a Creative Commons Attribution-NonCommercial-NoDerivatives 4.0 International (CC BY-NC-ND 4.0) License. 